\title{
Parámetros micrográficos foliares e histoquímica en la identificación de doce especies trepadoras medicinales rioplatenses (Argentina)
}

\author{
Micrographic foliar parameters and histochemistry in the \\ identification of twelve medicinal climbing plants of the Río de la \\ Plata area (Argentina)
}

\begin{abstract}
Hernández, Marcelo P.; Vanesa G. Perrotta; Noelia C. La Valle; Leandro M. Nughes; Marta N. Colares; María C. Novoa; Ana M. Arambarri*

Laboratorio de Morfología Comparada de Espermatófitas (LAMCE), Departamento de Ciencias Biológicas, Facultad de Ciencias Agrarias y Forestales, Universidad Nacional de La Plata, 60 y 119 , (1900) La Plata, Buenos Aires, Argentina.

* Autor corresponsal: anaramba@yahoo.com.ar; anaramba@agro.unlp.edu.ar
\end{abstract}

\section{RESUMEN}

El objetivo de este trabajo fue caracterizar doce especies de plantas trepadoras atendiendo los rasgos anatómicos y compuestos químicos de las hojas, que faciliten la identificación de los taxones en muestras enteras o fragmentadas de las mismas. Se analizó material fresco recolectado en el área de estudio y ejemplares de los herbarios (LP, LPAG). Para las preparaciones anatómicas se procedió con técnicas usuales para microscopía óptica. Se realizaron reacciones histoquímicas para identificar almidón, mucílagos, lípidos y taninos. Los principales rasgos micrográficos diferenciales fueron: tipo, distribución y posición de estomas e índice estomático; tipo y densidad de tricomas; forma de las caras de la vena media en corte transversal; tipo de haz vascular; tipo de mesofilo; estructuras secretoras; tipo de cristales y características del pecíolo en corte transversal. Sobre la base de los datos logrados se generaron tablas comparativas y una clave dicotómica para la determinación de las especies que constituyen una herramienta de valor en el control de calidad botánica.

Palabras clave - Anatomía, enredaderas, histoquímica, hojas, lianas.

\footnotetext{
Ref. bibliográfica: Hernández, M. P.; Perrotta, V. G.; La Valle, N. C.; Nughes, L. M.; Colares, M. N.; Novoa, M. C.; Arambarri, A. M. 2019. "Parámetros micrográficos foliares e histoquímica en la identificación de doce especies trepadoras medicinales rioplatenses (Argentina)". Lilloa 56 (1): 24-53. Fundación Miguel Lillo, Tucumán, Argentina. D.0.I.: doi.org/10.30550/j.lil/2019.56.1/3 > Recibido: 10/12/18 - Aceptado: 12/04/19 $>$ URL de la revista: http://lilloa.lillo.org.ar 


\section{ABSTRACT}

The aim of this paper was to get qualitative and quantitative leaf micrographic characters and to test chemical compounds to characterize the species in order to facilitate the identification of taxa from whole or fragmented samples of them. Fresh material was collected in the study area, and herbarium specimens (LP, LPAG) were analyzed. For the anatomical and histochemical preparations we proceeded with usual techniques for optical microscopy. Histochemical analysis to recognize starch, mucilage, lipophilic substances, and tannins were performed. The main differential micrographic features were: type, distribution and position of stomata and stomatal index; trichomes type and density; middle vein shapes in transection; vascular bundle type; mesophyll type; secretory structures; type of crystals and characteristics of the petiole in transection. Comparative tables and a dicotomic key using micrographic characters were generated as a tool for botanical quality control.

Keywords - Anatomy, climbing plants, histochemistry, leaves, lianas.

\section{INTRODUCCIÓN}

Este trabajo incluye los resultados de la línea de investigación seguida en el Proyecto sobre anatomía comparada de los órganos vegetativos de plantas usadas en la medicina popular en la región rioplatense, desarrollada en el Laboratorio de Morfología Comparada de Espermatófitas (LAMCE), Facultad de Ciencias Agrarias y Forestales, Universidad Nacional de La Plata. Dentro de la región rioplatense que se extiende desde Diamante en la provincia de Entre Ríos por el río Paraná, Delta superior, medio e inferior y el río de la Plata, el estudio se centra en las especies medicinales que habitan la parte inferior del Delta del Paraná, la isla Martín García y la ribera del Río de la Plata, incluyendo los humedales rioplatenses hasta la localidad de La Balandra, Partido de Berisso. Se han tomado como base los trabajos de Lahitte y Hurrell (1996); Pochettino et al. (1997); Lahitte et al. (2004); Hernández et al. (2009, 2010, 2013, 2015a) debiendo destacar la obra de Lahitte y Hurrell (2000) donde describen e ilustran 80 especies trepadoras nativas y exóticas de la región que nos ocupa. Este trabajo da continuidad a las investigaciones previas, dentro del proyecto ya mencionado, que dieron origen a nueve publicaciones (Novoa et al., 2012; Arambarri et al., 2013; Colares et al., 2014; Hernández et al., 2015b; Novoa y Arambarri, 2016; Arambarri et al., 2016; Colares et al., 2016, 2017; Perrotta et al., 2017). En lo que hace al uso en la medicina tradicional, de las hojas de las especies consideradas en el presente trabajo, los autores (Hieronymus, 1882; Domínguez, 1928; Ratera y Ratera, 1980; Martínez Crovetto, 1981; Lahitte y Hurrell, 1996; Marzocca, 1997; Lahitte y Hurrell, 2000; Lahitte et al., 2004; Barboza et al., 2006, 2009; Martínez, 2017; Volkmann, 2017) coinciden en la utilización por sus propiedades como galactógeno: Araujia odorata y A. sericifera; digestivo: Canavalia bonariensis; antidermatósico en uso externo: Clematis bonariensis y C. montevidensis e Ipomoea cairica, I. indica; para las vías respiratorias y cardiotónico: Lonicera japonica; cardiotónico, antisifilítico, diurético y 
hepático: Muehlenbeckia sagittifolia; sedante y ansiolítico: Passiflora caerulea y por su propiedad antiescorbútica: Tropaeolum majus y T. pentaphyllum. Teniendo en cuenta que la micrografía constituye un riguroso método de análisis aplicable sobre todo a los productos vegetales, basado en el reconocimiento y la valoración cualitativa y hasta cuantitativa de sus elementos histológicos (Spegazzini, 2007), en esta oportunidad se analizaron 12 especies de plantas trepadoras empleadas en la medicina popular rioplatense, cuyas características morfológicas tomadas de la bibliografía, se muestran en la Tabla 1. Se examinó la anatomía e histoquímica de las hojas de las 12 especies para obtener datos cualitativos y cuantitativos que permitan elaborar tablas comparativas y una clave dicotómica para su determinación.

Tabla 1. Morfología de las 12 especies estudiadas, características tomadas de: Lahitte y Hurrell (2000); Cabanillas y Hurrell (2012); Hiriart et al. (2018). Ref.: (E) enredadera; (L) liana.

\begin{tabular}{|c|c|c|c|c|c|}
\hline Taxa & $\begin{array}{c}\text { Tipo } \\
\text { biológico }\end{array}$ & Filotaxis & $\begin{array}{l}\text { Tipo de } \\
\text { hoja }\end{array}$ & $\begin{array}{c}\text { Lámina o } \\
\text { folíolo }\end{array}$ & Pecíolo \\
\hline $\begin{array}{l}\text { Araujia } \\
\text { odorata }\end{array}$ & $\mathrm{L}$ & opuesta & simple & $\begin{array}{l}\text { triangular- } \\
\text { hastada }\end{array}$ & no prensil \\
\hline $\begin{array}{l}\text { Araujia } \\
\text { sericifera }\end{array}$ & $\mathrm{L}$ & opuesta & simple & $\begin{array}{l}\text { ovado- } \\
\text { triangular }\end{array}$ & no prensil \\
\hline $\begin{array}{l}\text { Canavalia } \\
\text { bonariensis }\end{array}$ & $\mathrm{L}$ & alterna & $\begin{array}{l}\text { compuesta, } \\
\text { 3-foliolada }\end{array}$ & $\begin{array}{l}\text { folíolo } \\
\text { elíptico- } \\
\text { ovado, } \\
\text { entero }\end{array}$ & no prensil \\
\hline $\begin{array}{l}\text { Clematis } \\
\text { bonariensis }\end{array}$ & $\mathrm{L}$ & opuesta & $\begin{array}{l}\text { compuesta, } \\
\text { 3-foliolada }\end{array}$ & $\begin{array}{l}\text { folíolo } \\
\text { ovado- } \\
\text { elíptico, } \\
\text { entero }\end{array}$ & prensil \\
\hline $\begin{array}{l}\text { Clematis } \\
\text { montevidensis }\end{array}$ & L & opuesta & $\begin{array}{l}\text { compuesta, } \\
\text { 3-5-foliolada }\end{array}$ & $\begin{array}{c}\text { folíolo } \\
\text { ovado- } \\
\text { elíptico, } \\
\text { entero/ } \\
\text { dentado }\end{array}$ & prensil \\
\hline $\begin{array}{l}\text { Ipomoea } \\
\text { cairica }\end{array}$ & $\mathrm{L}$ & alterna & $\begin{array}{c}\text { simple, } \\
\text { palmado- } \\
\text { lobada }\end{array}$ & $\begin{array}{c}\text { lóbulo } \\
\text { lanceolado }\end{array}$ & no prensil \\
\hline $\begin{array}{l}\text { Ipomoea } \\
\text { indica }\end{array}$ & $\mathrm{L}$ & alterna & $\begin{array}{l}\text { simple, } \\
\text { entera o } \\
\text { 3-lobada }\end{array}$ & $\begin{array}{c}\text { ovado- } \\
\text { suborbicular }\end{array}$ & no prensil \\
\hline $\begin{array}{l}\text { Lonicera } \\
\text { japónica }\end{array}$ & L & opuesta & simple & ovada & no prensil \\
\hline $\begin{array}{l}\text { Muehlenbeckia } \\
\text { sagittifolia }\end{array}$ & $\mathrm{L}$ & alterna & simple & polimorfa & no prensil \\
\hline $\begin{array}{l}\text { Passiflora } \\
\text { caerulea }\end{array}$ & L & alterna & $\begin{array}{l}\text { simple, } \\
\text { palmado- } \\
\text { lobada }\end{array}$ & $\begin{array}{c}\text { lóbulo } \\
\text { elíptico- } \\
\text { lanceolado }\end{array}$ & no prensil \\
\hline $\begin{array}{l}\text { Tropaeolum } \\
\text { majus }\end{array}$ & $E$ & alterna & $\begin{array}{c}\text { simple } \\
\text { peltada }\end{array}$ & orbicular & prensil \\
\hline $\begin{array}{l}\text { Tropaeolum } \\
\text { pentaphyllum }\end{array}$ & $E$ & alterna & $\begin{array}{l}\text { compuesta, } \\
\text { palmado } \\
\text { 5-foliolada }\end{array}$ & $\begin{array}{c}\text { folíolo } \\
\text { elíptico- } \\
\text { lanceolado }\end{array}$ & prensil \\
\hline
\end{tabular}




\section{MATERIALES Y MÉTODOS}

\section{Material estudiado}

Se recolectaron ejemplares de las especies estudiadas en el área rioplatense, también se estudiaron ejemplares de las colecciones de los herbarios de la Facultad de Ciencias Naturales y Museo (LP) y de la Facultad de Agronomía (LPAG), ambas Instituciones pertenecientes a la Universidad Nacional de La Plata (UNLP). Para la nomenclatura de los taxones se tomó como referencia la base de datos del Instituto de Botánica Darwinion (consultado: julio 2018).

Material estudiado: ARGENTINA.

Araujia odorata (Hook. et Arn.) Fontella y Goyder [= Morrenia odorata (Hook et Arn.) Lindl.] (Apocynaceae): Prov. Buenos Aires, Pdo. La Plata, Parque Pereyra, sobre vías del ferrocarril, 14-III-1942, Cabrera 2058 (LP). Prov. Formosa, Dpto. Bermejo, Loc. Laguna Yema, 21-IX-2004, Bayón y Moreno 811 (LPAG). Prov. Jujuy, Dpto. Santa Bárbara, Loc. no indicada, 8-XI-1974, A.L. Cabrera et al. 25745 (LP).

Araujia sericifera Brot. (= A. hortorum E. Fourn.) (Apocynaceae): Prov. Buenos Aires, Pdo. La Plata, La Plata, 18-III-1995, Bayón 192 (LPAG); Pdo. Tigre, Delta del Paraná, 30-I-1939, G. Dawson 359 (LP). Pdo. Berisso, camino a La Balandra, 4-II-2017, M.P. Hernández 230 y 231 (LPAG).

Canavalia bonariensis Lindl. (Fabaceae): Prov. Buenos Aires, Pdo. La Plata, Isla Martín García, 26-XI-1983, N.M. Tur et al. 1830 (LP).

Clematis bonariensis Juss. ex DC. (Ranunculaceae): Prov. Buenos Aires, Pdo. Punta Indio, Bahía Samborombón, 16-XII-1933, E. F. Ringuelet s. n. (LPAG 1291).

Clematis montevidensis Spreng. (Ranunculaceae): Prov. Buenos Aires, Pdo. Tordi1lo, Tordillo, 29-II-2000, Aguiar 52/00 (LPAG). Prov. Formosa, Dpto. Bermejo, Loc. Laguna Yema, 22-IX-2004, Bayón y Moreno 844 (LPAG).

Ipomoea cairica (L.) Sweet (Convolvulaceae): Prov. Buenos Aires, Pdo. Magdalena, Reserva «El Destino», Fundación Elsa Shaw de Pearson, V-2016, Martínez Alonso 115 (LPAG); Pdo. La Plata, La Plata, Arboretum Jardín Botánico «C. Spegazzini», Facultad de Ciencias Agrarias y Forestales, UNLP, V-2016, Arambarri 517 (LPAG).

Ipomoea indica (Burm. f.) Merr. (Convolvulaceae): Prov. Buenos Aires, Pdo. La Plata, Loc. La Plata, Jardines Facultad de Ciencias Naturales y Museo, UNLP, V2016, Arambarri 512; 20-IV-2017, Montes de Oca y Arambarri 518 (LPAG); Loc. Manuel B. Gonnet, 27-IV-2017, M.P. Hernández 232, 233 (LPAG).

Lonicera japonica Thunb. (Caprifoliaceae): Prov. Buenos Aires, Pdo. Magdalena, Reserva «El Destino», Fundación Elsa Shaw de Pearson, 22-X-2014, M. P. Hernández 152 (LPAG).

Muehlenbeckia sagittifolia (Ortega) Meisn. (Polygonaceae): Prov. Buenos Aires, Pdo. La Plata, Loc. La Plata, Jardín Botánico y Arboretum «C. Spegazzini», Facultad Ciencias Agrarias y Forestales, (FCAyF), UNLP, V-2016, Arambarri 515 (LPAG); (FCAyF), UNLP, 15-XI-2016, Arambarri 520 (LPAG).

Passiflora caerulea L. (Passifloraceae): Buenos Aires, Pdo. La Plata, La Plata, (FCAyF), UNLP, III-2015, M. C. Novoa s. n.; 11-IV-2016, Montes de Oca y Arambarri 519 (LPAG). 
Tropaeolum majus L. (Tropaeolaceae): Prov. Buenos Aires, Pdo. La Plata, La Plata, (FCAyF), UNLP, 12-IX-2015, Arambarri 510 (LPAG). Pdo. Berisso, Villa Zula, 20-XII-2015, M. P. Hernández 158 (LPAG).

Tropaeolum penthaphyllum Lam. (Tropaeolaceae): Prov. Buenos Aires, Pdo. Magdalena, Reserva «El Destino», Fundación Elsa Shaw de Pearson, 02-II-2014, M. P. Hernández 153, 154 (LPAG).

\section{Métodos}

Microscopía óptica.- Para el estudio de la anatomía, el material fresco se lavó y conservó en una solución de formaldehido, ácido acético, alcohol etílico 70\% (FAA 70) (Johansen, 1940). El mismo procedimiento de conservación se usó para el material de herbario, previa hidratación durante $72 \mathrm{~h}$ en agua más una gota de detergente en estufa a $25-30^{\circ} \mathrm{C}$. Para el estudio de los caracteres topográficos del tejido epidérmico y recuentos a aplicar en la determinación de la densidad e índices se obtuvieron láminas y folíolos transparentes empleando la Técnica 5-5-5 (Arambarri, 2018). Para el estudio de las estructuras se realizaron cortes transversales en la parte media de cada parte de la hoja simple: pecíolo y lámina y de la hoja compuesta: pecíolo, raquis, peciólulo, folíolo. Los cortes fueron realizados a mano alzada, seleccionando y decolorando los que mostraban el menor número de capas celulares. El material clarificado y los cortes transversales decolorados y lavados, fueron teñidos con solución de safranina alcohólica (80\%) y tinción doble sucesiva, Azul Alcian-Safranina o Azul Alcian-Fucsina básica (Luque et al., 1996), montando en gelatina-glicerina y sellando con esmalte de uñas. Los diafanizados se emplearon en la obtención de los datos en vista frontal de la epidermis, en la parte media-central de los semilimbos de la lámina o folíolo y sobre ambas epidermis. Se determinaron caracteres cualitativos como modelo de las paredes anticlinales de las células epidérmicas, ornamentación cuticular, tipo de estomas y tricomas. Los caracteres cuantitativos se obtuvieron al realizar el conteo de células epidérmicas, estomas y tricomas en cuatro campos sobre ambos semilimbos y ambas caras. Las células que se ubicaban en el borde del campo visual, quedando visible menos de la mitad no fueron consideradas en el recuento. Con los datos se determinó la densidad de células, estomas y tricomas por unidad de superficie $\left(\mathrm{mm}^{2}\right)$ y se calcularon los índices estomático y piloso. Para el cálculo del índice estomático se aplicó la fórmula de Salisbury (1927): IE\% [ $\mathrm{n}^{\mathrm{o}}$ de estomas / $\left(\mathrm{n}^{\circ}\right.$ de estomas $+\mathrm{n}^{\mathrm{o}}$ células epidérmicas)] x 100. La misma fórmula, pero reemplazando los estomas por los pelos o tricomas se empleó para calcular el índice piloso, ambos expresados en porcentaje (IP\%) (Hernández y Albornoz, 2001). También profundizando el enfoque desde la epidermis adaxial se contaron las células en empalizada debajo de cuatro células epidérmicas calculando el índice de empalizada adaxial para cada una de las especies, empleando la fórmula (número de células en empalizada / cuatro células epidérmicas) de Zornig y Weiss (1925).

En los cortes transversales de la lámina se consideraron los caracteres: caras de la vena media dando la forma de la sección (biconvexa, plano-convexa o cóncavoconvexa) y su estructura interna, tipo y características de las células del mesofilo, 
cristales y estructuras secretoras. En los cortes transversales del pecíolo se determinó su contorno, destacando los tejidos y su arreglo, estructuras secretoras y cristales. La distribución de los tejidos formando las estructuras y recuento celular se realizaron con un microscopio óptico (MO) Leitz SM Lux equipado con cámara clara. Las microfotografías fueron tomadas con MO Gemalux XSZ-H equipado con cámara Motic y software Motic Image Plus 2.0 y con un MO Nikon E200 LED, equipado con cámara digital y software SE Premium. La terminología y tipos de estomas están de acuerdo con Metcalfe y Chalk (1979), para los estomas también se consultó la clasificación de Ash et al. (1999).

Técnicas histoquímicas.- Sobre cortes transversales de lámina y pecíolo se aplicaron las técnicas de identificación de almidón con Lugol (iodo y ioduro de potasio, IKI) (Ruzin, 1999); para sustancias lipofílicas se empleó una solución alcohólica saturada de Sudan IV (Zarlavsky, 2014) y Oil red «O»(Gurr, 1971); para mucílagos se utilizó azul brillante de cresilo 1\% (Cosa et al., 2014) y para taninos se empleó el reactivo cloruro férrico al 10\% y carbonato de sodio al 2\% (Zarlavsky, 2014).

Se analizaron las hojas de las 12 especies. Los caracteres histológico-estructurales destacables de las especies se ilustran en las figuras 1-6. Se presenta la descripción de los tejidos y estructuras que se complementa con datos de la anatomía indicados en la Tabla 2; los parámetros micrográficos epidérmicos son indicados en las tablas 3 y 4; los compuestos químicos identificados y las estructuras secretoras se detallan en la Tabla 5. En el Apéndice se presentan las especies - por orden alfabético de género y especie-, nombre vernáculo frecuentemente empleado, usos y la actividad biológica de las hojas.

\section{RESULTADOS \\ Descripción comparativa de la anatomía foliar de las especies}

\section{Araujia odorata y $A$. sericifera}

Lámina.- En vista frontal las epidermis, adaxial y abaxial, muestran células poligonales con paredes anticlinales rectilíneas, más pequeñas y numerosas en $A$. odorata (Tablas 3 y 4); la pared periclinal externa está cubierta con abundantes ceras que se manifiestan en forma de estrías cuticulares y ornamentan los estomas y los tricomas; estos son eglandulares, pluricelulares, uniseriados, rodeados en su base por 5-8 células epidérmicas radiadas. El pelo generalmente está formado por 3-4 células, una en la epidermis con paredes gruesas y cutinizadas, las dos o tres células expuestas presentan longitud en orden creciente hacia la parte distal, con la última célula aguzada. La totalidad del tricoma presenta ceras produciendo una superficie verrucosa (Fig. 1A). La pubescencia es más abundante en $A$. sericifera (Tablas 3 y 4). En $A$. odorata ambas epidermis presentan estomas de los tipos braquiparacíticos, paralelocíticos o anfibraquiparacíticos, ciclocíticos y anficiclocíticos (Fig. 1B) distribuidos de manera desordenada en ambas epidermis, mientras que en $A$. sericifera 


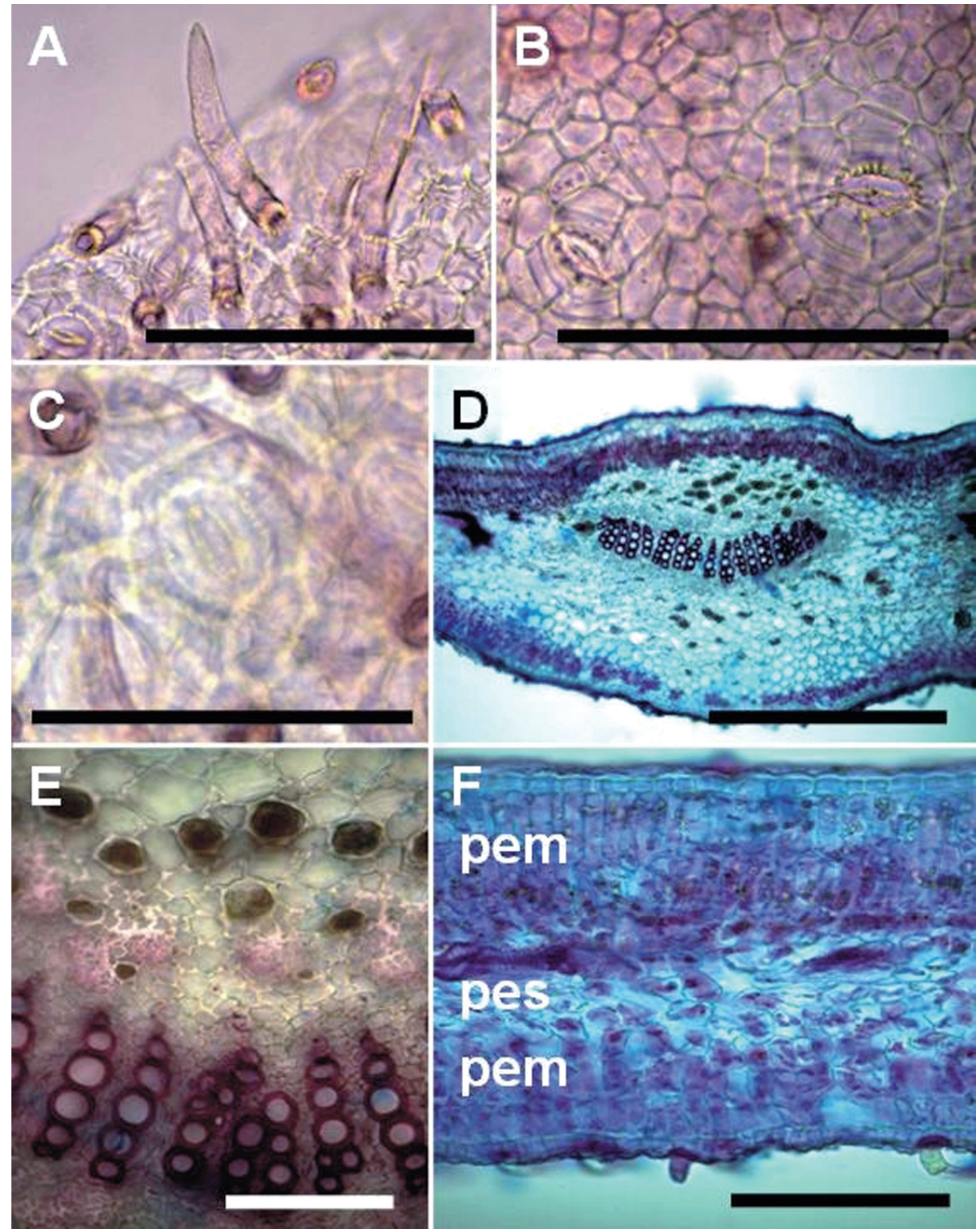

Fig. 1. Araujia odorata y A. sericifera. A) Epidermis mostrando ornamentación cuticular y tricomas, con célula basal cutinizada y dos células expuestas verrucosas. B) Epidermis de $A$. odorata mostrando las células epidérmicas pequeñas con paredes anticlinales rectilíneas y dos estomas anficiclocíticos. C) Epidermis y estoma braquiparatetracítico de A. sericifera. D) Sección transversal de la vena media biconvexa, mostrando la continuidad del clorénquima sobre ambas caras, el haz bicolateral central, rodeado de parénquima con los tubos laticíferos en el lado abaxial, pero predominando hacia la cara adaxial, sobre el haz vascular. E) Detalle de los tubos laticíferos en corte transversal, mostrando el contorno poligonal y contenido oscuro. F) Mesofilo isolateral de $A$. odorata. Ref. : pem, parénquima en empalizada; pes, parénquima esponjoso. Escalas: $\mathrm{A}, \mathrm{B}, \mathrm{E}, \mathrm{F}: 100 \mu \mathrm{m}$; C: $70 \mu \mathrm{m}$; D: $500 \mu \mathrm{m}$. 
lo estomas son braquiparacíticos, anomocíticos y braquiparatetracíticos (Fig. 1C), distribuidos predominantemente en la epidermis abaxial (Tabla 2). En ambas especies, en la sección transversal las epidermis son unistratas, con las células, tanto en la epidermis adaxial como abaxial cuadrangulares con paredes engrosadas, en especial las periclinales, externa e interna; la continuidad epidérmica se ve interrumpida por los estomas, los cuales se ubican hundidos con respecto a las restantes células epidérmicas en Araujia odorata y a nivel en $A$. sericifera. La vena media, en ambas especies, muestra convexidad adaxial y abaxial leve (Fig. 1D; Tabla 2); en $A$. odorata, en posición subepidérmica hay 2-3 capas de colénquima angular, adaxial y abaxial, mientras que en $A$. sericifera hay 4-5 capas de colénquima angular adaxial y 7-8 capas hacia la cara abaxial; en ambas especies a continuación del colénquima, hay clorénquima que se prolonga desde las alas; en posición medular hay un haz en forma de arco, circundado por parénquima, el cual está atravesado por numerosos tubos laticíferos de sección poligonal, ubicados sobre y debajo del haz vascular, predominando sobre el lado adaxial (Fig. 1D, E; Tabla 2). El mesofilo en $A$. odorata está formado por parénquima en empalizada adaxial denso y abaxial laxo y entre ellos el parénquima esponjoso (Fig. 1F; Tabla 2), mientras que en $A$. sericifera el parénquima en empalizada adaxial está acompañado de parénquima esponjoso abaxial (Tabla 2), sin embargo, en algunas muestras se observa una tendencia al tipo isolateral. En ambas especies se observan células idioblásticas con drusas (Tabla 5) y los haces vasculares colaterales de menor tamaño que se localizan en el parénquima esponjoso, presentan vaina parenquimática notable.

Tabla 2. Características anatómicas selectas de las hojas de las 12 especies analizadas. Ref.: (anfi-) anfistomática; (c/lob) con lóbulos ventrales; (dorsivent.) dorsiventral; (hipo-) hipostomática; (s/lob) sin lóbulos ventrales.

\begin{tabular}{|l|c|c|c|c|c|c|}
\hline \multicolumn{1}{|c|}{ Taxa } & Lámina & $\begin{array}{c}\text { Vena } \\
\text { media }\end{array}$ & $\begin{array}{c}\text { Tipo de } \\
\text { haz }\end{array}$ & Mesofilo & \multicolumn{2}{c|}{ Pecíolo } \\
\hline $\begin{array}{l}\text { Araujia } \\
\text { odorata }\end{array}$ & anfi- & biconvexa & bicolateral & $\begin{array}{c}\text { isolateral } \\
2-3: 4-5: 2\end{array}$ & redonteado & c/lob \\
\hline $\begin{array}{l}\text { Araujia } \\
\text { sericifera }\end{array}$ & hipo- & biconvexa & bicolateral & $\begin{array}{c}\text { dorsivent } \\
2: 5-6\end{array}$ & redondeado & c/lob \\
\hline $\begin{array}{l}\text { Canavalia } \\
\text { bonariensis }\end{array}$ & hipo- & $\begin{array}{c}\text { cóncavo- } \\
\text { convexa }\end{array}$ & colateral & $\begin{array}{c}\text { dorsivent } \\
1: 5-6\end{array}$ & redondeado & s/lob \\
\hline $\begin{array}{l}\text { Clematis } \\
\text { bonariensis }\end{array}$ & anfi- & $\begin{array}{c}\text { cóncavo- } \\
\text { convexa }\end{array}$ & colateral & $\begin{array}{c}\text { dorsivent } \\
2-3: 4-6\end{array}$ & pentagonal & c/lob \\
\hline $\begin{array}{l}\text { Clematis } \\
\text { montevidensis }\end{array}$ & anfi- & $\begin{array}{c}\text { plano- } \\
\text { convexa }\end{array}$ & colateral & $\begin{array}{c}\text { dorsivent } \\
2-3: 5-6\end{array}$ & pentagonal & c/lob \\
\hline $\begin{array}{l}\text { Ipomoea } \\
\text { cairica }\end{array}$ & hipo- & biconvexa & bicolateral & $\begin{array}{c}\text { dorsivent } \\
1-2: 4-5\end{array}$ & redondeado & c/lob \\
\hline $\begin{array}{l}\text { Ipomoea } \\
\text { indica }\end{array}$ & anfi- & biconvexa & bicolateral & $\begin{array}{c}\text { dorsivent } \\
2-3: 4-5\end{array}$ & redondeado & $\mathrm{c} / \mathrm{lob}$ \\
\hline $\begin{array}{l}\text { Lonicera } \\
\text { japonica }\end{array}$ & hipo- & biconvexa & colateral & $\begin{array}{c}\text { dorsivent } \\
1-3: 4-6\end{array}$ & semicircular & $\mathrm{s} / \mathrm{lob}$ \\
\hline $\begin{array}{l}\text { Muehlenbeckia } \\
\text { sagittifolia }\end{array}$ & anfi- & biconvexa & colateral & $\begin{array}{c}\text { dorsivent } \\
1-2: 5-6\end{array}$ & pentagonal & $\mathrm{c} / \mathrm{lob}$ \\
\hline $\begin{array}{l}\text { Passiflora } \\
\text { caerulea }\end{array}$ & hipo- & $\begin{array}{l}\text { cóncavo- } \\
\text { convexa }\end{array}$ & colateral & $\begin{array}{c}\text { isolateral } \\
1: 3-5: 1\end{array}$ & redondeado & c/lob \\
\hline $\begin{array}{l}\text { Tropaeolum } \\
\text { majus }\end{array}$ & anfi- & biconvexa & colateral & $\begin{array}{c}\text { dorsivent } \\
1: 4-5\end{array}$ & circular & s/lob \\
\hline $\begin{array}{l}\text { Tropaeolum } \\
\text { pentaphyllum }\end{array}$ & hipo- & biconvexa & colateral & dorsivent & circular & s/lob \\
\hline
\end{tabular}


Pecíolo.- En ambas especies es pubescente en toda su periferia, en corte transversal la cara ventral es cóncava y cada lóbulo es irrigado por un haz vascular. La epidermis está formada por células cuadrangular a rectangulares, en algunos sectores con su eje más largo perpendicular a la superficie, con paredes engrosadas y cutícula gruesa, notablemente estriada. En posición subepidérmica se hallan 2-4 capas de colénquima angular, continuo, seguido de parénquima cortical reservante, con drusas. En el sector medular se ubica un haz bicolateral y numerosos tubos laticíferos.

\section{Canavalia bonariensis}

Lámina._En vista frontal la epidermis adaxial muestra células poligonales con paredes anticlinales curvado-onduladas, con notables ceras epicuticulares (Fig. 2A), mientras en la abaxial son sinuosas y algunas células de esta epidermis, ubicadas sobre las venas, contienen maclas gemelas (Fig. 2B). Los estomas son predominantemente paracíticos, ocasionalmente se observan algunos anisocíticos (Fig. 2B). Los tricomas glandulares y eglandulares son escasos. Los primeros con un pie corto y cabeza unicelular con forma de lámpara (Fig. 2A). Los eglandulares bicelulares, con la célula basal muy corta, con paredes gruesas, cutinizadas y la terminal larga y aguda, con las paredes gruesas y lisas. La unión entre las dos células es frágil, ya que frecuentemente se encuentran las células separadas (Fig. 2C; Tablas 3 y 4). Profundizando el enfoque se puede observa la vaina cristalífera de las venas. En la sección transversal las epidermis son unistratas, las células de la epidermis adaxial son rectangulares, cubiertas por cutícula delgada, de tamaño notoriamente más grandes que en la epidermis abaxial, la que además es interrumpida por estomas ubicados a nivel respecto a las restantes células epidérmicas. La vena media es cóncava en la cara adaxial (considerando la vena respecto a las alas, Tabla 2); en posición subepidérmica hay 3-4 capas de colénquima angular, adaxial y abaxial; en posición medular se encuentra un haz con xilema adaxial y floema abaxial, ambos con casquetes de esclerénquima de 3-5 capas de espesor, que se fusionan con el parénquima esclerificado formando un anillo; el conjunto está rodeado por la vaina cristalífera con cristales solitarios y maclas. El mesofilo está formado por parénquima en empalizada de células rectangulares cortas en posición adaxial y el parénquima esponjoso laxo, abaxial (Tabla 2). En este último se observan los haces vasculares de menor tamaño con casquetes de fibras, pero cuando son muy pequeños presentan solo vaina parenquimática notable. Pecíolo. Glabro, en corte transversal (Tabla 2), con la epidermis formada por células cuadrangulares con la pared periclinal externa engrosada y cutícula lisa. En posición subepidérmica, el colénquima angular, continuo, está formado por 1-2 estratos seguido de parénquima cortical con numerosas células con contenido altamente coloreado, posiblemente conteniendo pigmentos antociánicos, ya que dio negativo el test para taninos. La capa más interna de la corteza, forma una vaina cristalífera alrededor del anillo de esclerénquima. Este rodea el tejido vascular. En el floema se destacan células con contenido pigmentado similar a las del parénquima cortical. En el parénquima del xilema y radios se determinó la presencia de almidón (Tabla 5). La médula es parenquimática. 
Raquis. - Similar al pecíolo, pero con un lóbulo que lleva un haz vascular.

Peciólulo.- En corte transversal de contorno redondeado. La epidermis formada por células cuadrangulares conteniendo maclas, seguida por colénquima angular e internamente el parénquima cortical donde se destacan células con sustancia pigmentada como las existentes en el folíolo. En la médula se encuentra un haz colateral con forma de $\mathrm{U}$ abierta hacia la cara adaxial.

\section{Clematis bonariensis y Clematis montevidensis}

Lámina._En vista frontal las epidermis adaxial y abaxial muestran células poligonales con paredes rectilíneas a levemente curvadas y cutícula ligeramente estriada; los estomas son anomocíticos (Fig. 2D) y los tricomas escasos presentes en todas las partes de la hoja, son de tipo glandular y eglandular. Los primeros claviformes, con una célula basal corta, cutinizada y una célula terminal oblonga con pared muy delgada (Fig. 2D); los eglandulares, simples, bicelulares, con una célula basal muy corta, cutinizada y la apical larga, aguda (Tablas 3 y 4). En la sección transversal las epidermis son unistratas, las células de la epidermis adaxial son rectangulares con la pared periclinal externa gruesa, cubiertas por cutícula delgada e interrumpida por estomas; estas células son de mayor tamaño que en la epidermis abaxial, en la cual, predominan los estomas ubicados a nivel respecto a las restantes células epidérmicas (Fig. 2E). La vena media es cóncava en la cara adaxial (en relación con las alas) en C. bonariensis y plana en C. montevidensis (Tabla 2); en posición subepidérmica hay colénquima angular, 1-2 capas adaxial y 4-6 abaxial y en posición medular un haz colateral circundado por parénquima. El mesofilo está formado por parénquima en empalizada de células rectangulares muy cortas hacia el lado adaxial y parénquima esponjoso laxo, abaxial (Fig. 2E; Tabla 2). En este último se observan los haces vasculares menores, con vaina parenquimática.

Pecíolo.- Subglabro, en corte transversal es redondeado con cinco lóbulos y una ligera convexidad ventral (Fig. 2F, Tabla 2). La epidermis está formada por células cuadrangulares con la pared periclinal externa engrosada con cutícula gruesa, estomas a nivel y la célula basal de los tricomas. En posición subepidérmica, el colénquima angular, continuo, está formado por 1-4 estratos que se distribuyen, con el mayor espesor en los lóbulos, y el menor en los sectores interlobulares, donde la epidermis se presenta colenquimática. La capa más interna del parénquima cortical forma la vaina parenquimática que rodea el anillo esclerenquimático que a través de los radios medulares lignificados forma con la médula parcialmente lignificada una estructura de sostén atravesada por 6-8 haces vasculares colaterales de diferentes tamaños y dispuestos en eustela. De estos haces vasculares, cinco corresponden a los lóbulos, uno mayor a la cara ventral y a veces, están presentes dos haces menores en los sectores interlobulares dorso-laterales (Fig. 2F). 


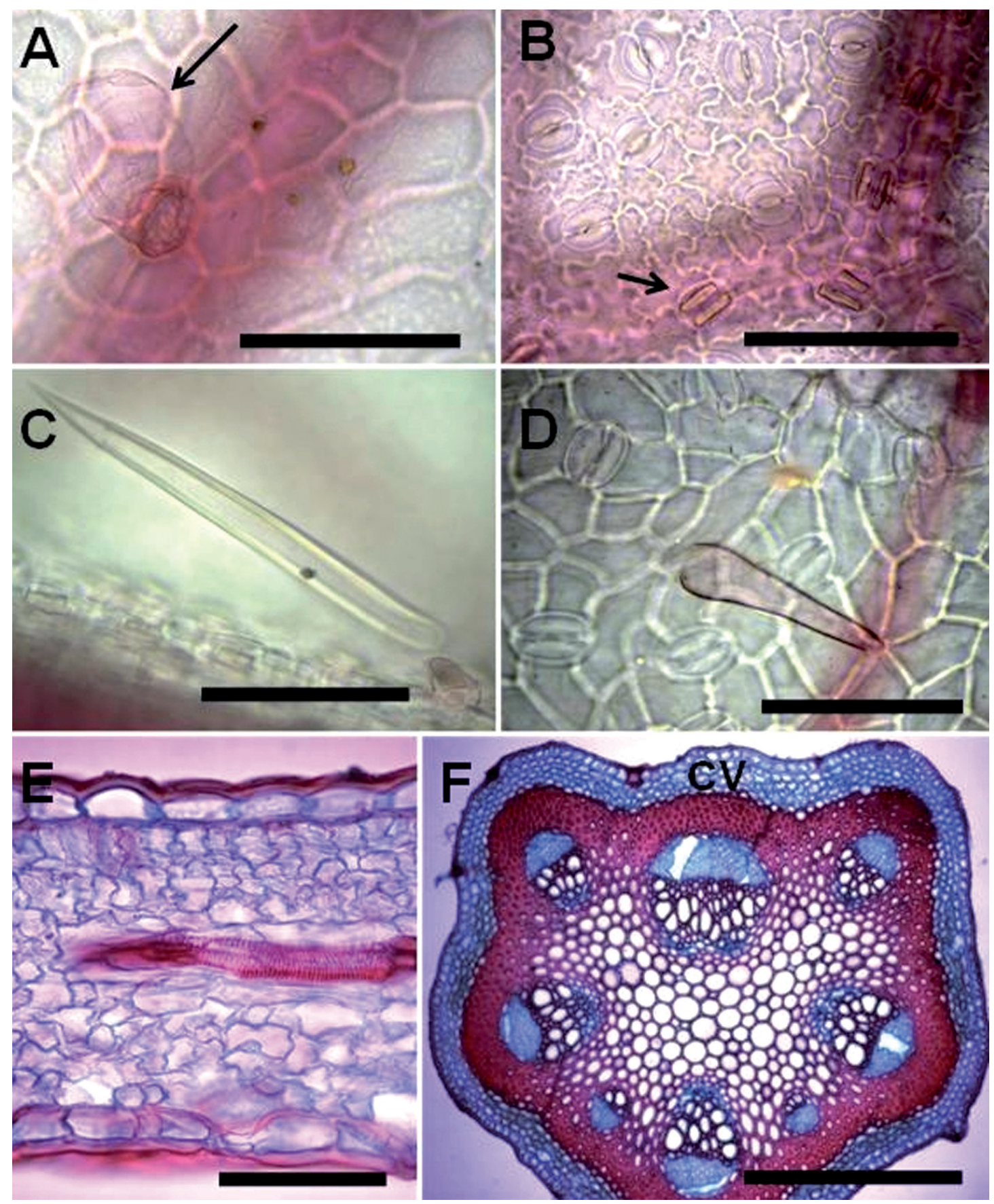

Fig. 2. Canavalia bonariensis, Clematis bonariensis y C. montevidensis. A-C) Canavalia bonariensis. A) Epidermis adaxial mostrando las células epidérmicas cubiertas con ceras epicuticulares y un tricoma glandular (flecha). B) Epidermis abaxial mostrando las células epidérmicas con paredes anticlinales sinuosas, los estomas paracíticos y las maclas gemelas en las células epidérmicas sobre las venas (flecha). C) Tricoma eglandular con la célula terminal aguda, separada de la célula basal cutinizada. D-F) Clematis spp. D) Epidermis mostrando las células epidérmicas con paredes anticlinales rectilíneas a ligeramente curvadas, estomas anomocíticos y tricoma claviforme. E) Corte transversal de lámina mostrando epidermis adaxial y abaxial; estoma, en la cara abaxial, a nivel; mesofilo dorsiventral y un haz vascular menor con vaina parenquimática. F) Sección transversal del pecíolo mostrando su estructura altamente esclerificada. Ref.: cv, cara ventral. Escalas: A-E: $100 \mu \mathrm{m}$; F: $500 \mu \mathrm{m}$. 
Tabla 3. Parámetros micrográficos, densidades e índices de la epidermis adaxial. Ref.: (c/mm²) células epidérmicas por milímetro cuadrado (unidad de superficie); $\left(\mathrm{e} / \mathrm{mm}^{2}\right)$ estomas por unidad de superficie; $\left(\mathrm{t} / \mathrm{mm}^{2}\right)$ tricomas por unidad de superficie; (IE) índice estomático; (IP) índice piloso; (Emp) índice de empalizada.

\begin{tabular}{|l|c|c|c|c|c|c|}
\hline \multicolumn{1}{|c|}{ TAXA } & \multicolumn{5}{|c|}{ EPIDERMIS ADAXIAL } \\
\hline & $\mathbf{c}$ / $\mathbf{m m 2}$ & $\mathbf{e} / \mathbf{m m 2}$ & $\mathbf{t} \mathbf{~ m m 2}$ & $\mathbf{I E} \%$ & $\mathbf{I P \%}$ & Emp \\
\hline $\begin{array}{l}\text { Araujia } \\
\text { odorata }\end{array}$ & 7628,78 & 75,75 & 22,72 & 0,98 & 0,30 & 1,50 \\
\hline $\begin{array}{l}\text { Araujia } \\
\text { sericifera }\end{array}$ & 1677,78 & 0 & 25,86 & 0 & 1,52 & 7,00 \\
\hline $\begin{array}{l}\text { Canavalia } \\
\text { bonariensis }\end{array}$ & 882,75 & 0 & 1,72 & 0 & 0,19 & 3,83 \\
\hline $\begin{array}{l}\text { Clematis } \\
\text { bonariensis }\end{array}$ & 948,03 & 12,87 & 6,06 & 1,34 & 0,63 & 7,50 \\
\hline $\begin{array}{l}\text { Clematis } \\
\text { montevidensis }\end{array}$ & 754,54 & 75,75 & 3,03 & 9,12 & 0,40 & 7,16 \\
\hline $\begin{array}{l}\text { Ipomoea } \\
\text { cairica }\end{array}$ & 515,15 & 0 & 7,57 & 0 & 1,45 & 10,75 \\
\hline $\begin{array}{l}\text { Ipomoea } \\
\text { indica }\end{array}$ & 1227,27 & 30,30 & 15,15 & 2,41 & 1,22 & 7,00 \\
\hline $\begin{array}{l}\text { Lonicera } \\
\text { japonica }\end{array}$ & 981,06 & 0 & 0 & 0 & 0 & 9,50 \\
\hline $\begin{array}{l}\text { Muehlenbeckia } \\
\text { sagittifolia }\end{array}$ & 321,96 & 26,51 & 0 & 7,61 & 0 & 5,16 \\
\hline $\begin{array}{l}\text { Passiflora } \\
\text { caerulea }\end{array}$ & 1238,64 & 0 & 0 & 0 & 0 & 8,00 \\
\hline $\begin{array}{l}\text { Tropaeolum } \\
\text { majus }\end{array}$ & 772,73 & 113,64 & 0 & 12,82 & 0 & 12,75 \\
\hline $\begin{array}{l}\text { Tropaeolum } \\
\text { pentaphyllum }\end{array}$ & 299,24 & 0 & 0 & 0 & 0 & 9,25 \\
\hline
\end{tabular}

Tabla 4. Parámetros micrográficos, densidades e índices de la epidermis abaxial. Ref.: (c/mm ${ }^{2}$ ) células por milímetro cuadrado (unidad de superficie); $\left(\mathrm{e} / \mathrm{mm}^{2}\right.$ ) estomas por unidad de superficie; $\left(\mathrm{t} / \mathrm{mm}^{2}\right)$ tricomas por unidad de superficie; (IE) índice estomático; (IP) índice piloso; (Emp) índice de empalizada.

\begin{tabular}{|c|c|c|c|c|c|c|}
\hline \multirow{3}{*}{ TAXA } & \multicolumn{6}{|c|}{$\begin{array}{l}\text { EPIDERMIS ABAXIAL } \\
\end{array}$} \\
\hline & \multicolumn{3}{|c|}{ Densidades } & \multicolumn{3}{|c|}{ Índices } \\
\hline & $\mathrm{c} / \mathrm{mm} 2$ & $\mathrm{e} / \mathrm{mm} 2$ & $\mathrm{t} / \mathrm{mm} 2$ & IE\% & IP\% & Emp \\
\hline $\begin{array}{l}\text { Araujia } \\
\text { odorata }\end{array}$ & 9965,90 & 208,33 & 246,21 & 2,05 & 2,41 & 0 \\
\hline $\begin{array}{l}\text { Araujia } \\
\text { sericifera }\end{array}$ & 2156,89 & 268,96 & 437,93 & 7,26 & 16,88 & 0 \\
\hline $\begin{array}{l}\text { Canavalia } \\
\text { bonariensis }\end{array}$ & 1718,96 & 291,37 & 0 & 14,49 & 0 & 0 \\
\hline $\begin{array}{l}\text { Clematis } \\
\text { bonariensis }\end{array}$ & 1318,18 & 245,45 & 5 & 15,24 & 0,54 & 0 \\
\hline $\begin{array}{l}\text { Clematis } \\
\text { montevidensis }\end{array}$ & 926,66 & 166,66 & 5 & 15,24 & 0,54 & 0 \\
\hline $\begin{array}{l}\text { Ipomoea } \\
\text { cairica }\end{array}$ & 814,39 & 83,33 & 15,15 & 9,28 & 1,83 & 0 \\
\hline $\begin{array}{l}\text { Ipomoea } \\
\text { indica }\end{array}$ & 1462,12 & 321,97 & 60,60 & 18,05 & 3,98 & 0 \\
\hline $\begin{array}{l}\text { Lonicera } \\
\text { japonica }\end{array}$ & 2806,81 & 397,72 & 0 & 12,53 & 0 & 0 \\
\hline $\begin{array}{l}\text { Muehlenbeckia } \\
\text { sagittifolia }\end{array}$ & 541,66 & 113,63 & 0 & 17,34 & 0 & 0 \\
\hline $\begin{array}{l}\text { Passiflora } \\
\text { caerulea }\end{array}$ & 1280,30 & 409,09 & 0 & 24,21 & 0 & 5,75 \\
\hline $\begin{array}{l}\text { Tropaeolum } \\
\text { majus }\end{array}$ & 866,67 & 360,60 & 15,15 & 29,38 & 1,72 & 0 \\
\hline $\begin{array}{l}\text { Tropaeolum } \\
\text { pentaphyllum }\end{array}$ & 336,36 & 81,82 & 0 & 19,56 & 0 & 0 \\
\hline
\end{tabular}


Raquis. - Similar al pecíolo con la cara ventral cóncava y dos lóbulos ventrales marcados.

Peciólulo.- Semejante al pecíolo y raquis pero a diferencia del pecíolo, el haz vascular de la cara ventral es el menor.

\section{Ipomoea cairica}

Lámina._En vista frontal ambas epidermis muestran células poligonales con paredes anticlinales sinuosas (Fig. 3A), con la pared periclinal externa con estrías cuticulares. Los estomas son paracíticos, ocasionalmente anomocíticos y anisocíticos ornamentados con las estrías cuticulares y dispuestos de manera desordenada. Sobre ambas caras y en el borde laminar hay gran cantidad de tricomas glandulares y eglandulares. Los primeros con pie corto, formado por una célula con paredes fuertemente cutinizadas y cabeza pluricelular (Fig. 3A). Los eglandulares, pluricelulares, con una base uni o biseriada, con varias células hasta la apical aguda; excepto la célula terminal, las restantes presentan conspicuas estrías cuticulares (Fig. 3B). En la sección transversal las epidermis son unistratas, las células de la epidermis adaxial son rectangulares con paredes delgadas; la cutícula es delgada y estriada; su tamaño es mayor que en la epidermis abaxial, que lleva los estomas, ubicados a nivel o ligeramente elevados respecto a las restantes células epidérmicas. La vena media muestra convexidad adaxial prominente formando un lóbulo agudo, mientras el abaxial es convexo-redondeado (Fig. 3C; Tabla 2); en posición subepidérmica hay 2-3 capas de colénquima angular adaxial y parénquima en empalizada que se prolonga desde las alas; sobre la cara abaxial hay parénquima o solo una capa de colénquima; en posición medular está el haz vascular (Tabla 2), circundado por parénquima con conductos esquizógenos cuyo contenido en forma de gotas dio reacción positiva para sustancias lipofílicas (Fig. 3C). Tanto en el floema como en el parénquima de la vena media hay drusas pequeñas (Tabla 5). El mesofilo está formado por el parénquima en empalizada de células muy cortas adaxial y parénquima esponjoso laxo abaxial (Fig. 3C; Tabla 2). Los haces vasculares de menor tamaño que se localizan en el parénquima esponjoso, presentan vaina parenquimática notable.

Pecíolo.- Glabro, en corte transversal con lóbulos ventrales irrigados por los respectivos haces vasculares (Tabla 2). La epidermis está formada por células cuadrangulares con las paredes y cutícula delgadas, células que en la cara ventral se presentan papilosas. Existe una hipodermis cristalífera con drusas (Fig. 3D), y a continuación 1 a 5 estratos de colénquima angular-lagunar continuo; más internamente se encuentra parénquima cortical de células grandes donde se distinguen conductos secretores con gotas de aceites. En la zona medular se localiza el haz bicolateral en forma de arco con capa amilífera junto al floema abaxial, el cual presenta drusas pequeñas semejantes a las del parénquima (Tabla 5). 

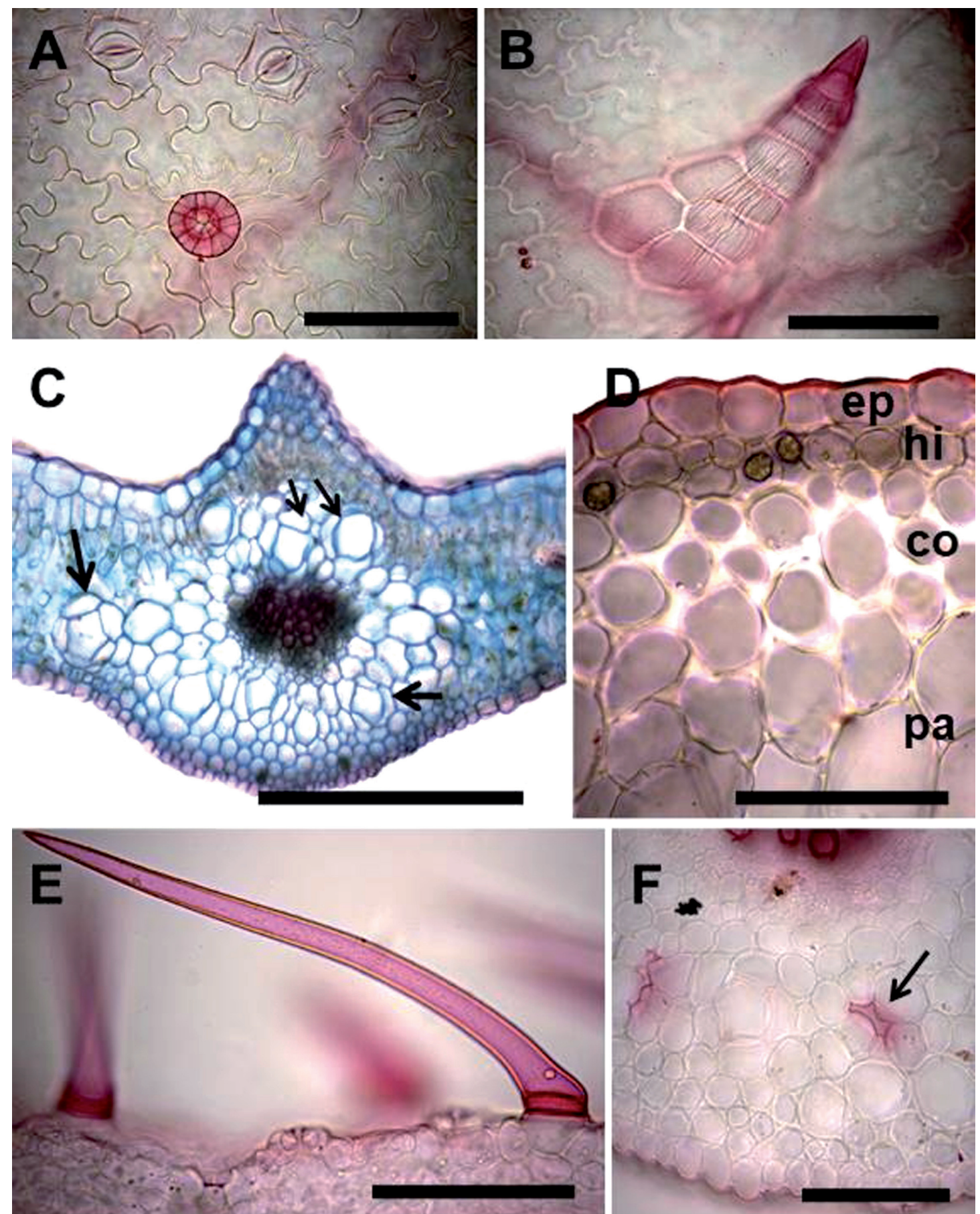

Fig. 3. Ipomoea cairica e I. indica. A-D) I. cairica. A) Epidermis abaxial mostrando las células epidérmicas con paredes anticlinales sinuosas, estomas paracíticos y un tricoma glandular con cabeza pluricelular. B) Epidermis adaxial mostrando las características de los tricomas eglandulares. C) Sección transversal de la vena media con característica convexidad adaxial, aguda, presente en ambas especies estudiadas; las flechas indican los conductos esquizógenos en el parénquima de la vena media de $I$. cairica. D) Porción de la sección transversal del pecíolo mostrando los tejidos y en especial la hipodermis cristalífera presente en ambas especies. E, F) I. indica. E) Tricoma eglandular. F) Células laticíferas en la vena media (flecha). Ref.: co, colénquima; ep, epidermis; hi, hipodermis; pa, parénquima. Escalas: A, B, D-F: $100 \mu \mathrm{m}$; C: $400 \mu \mathrm{m}$. 


\section{Ipomoea indica}

Lámina._En vista frontal, la epidermis adaxial muestra células poligonales con paredes anticlinales onduladas, mientras que en la abaxial son sinuosas; en ambas epidermis la pared periclinal externa de las células presenta estrías cuticulares. Los estomas, son anomocíticos, anisocíticos y paracíticos, ornamentados con las estrías cuticulares y dispuestos de manera desordenada, predominando los paracíticos en la cara abaxial donde son muy numerosos (Tablas 2, 3 y 4). Sobre la superficie de ambas caras hay gran cantidad de tricomas glandulares y eglandulares (Tablas 3 y 4). Los glandulares con pie corto, formado por una célula con paredes cutinizadas y cabeza 2-4 celular. Los eglandulares, con 1-4 células basales cortas, al menos una altamente cutinizada y la célula terminal larga, con las paredes gruesas y el ápice agudo (Fig. 3E). Estos tricomas están rodeados por 2-5 células epidérmicas basales. En la sección transversal se diferencia de I. cairica por la posición elevada de los estomas respecto a las restantes células epidérmicas (Fig. 3E). La vena media presenta la convexidad adaxial igual a I. cairica, pero en posición subepidérmica hay 5-6 capas de colénquima angular adaxial y parénquima colenquimatoso sobre el lado abaxial; en posición medular, en el parénquima que circunda el haz vascular (Tabla 2) se destacan dos tipos de estructuras secretoras: los conductos esquizógenos y las células secretoras; estas últimas en el corte transversal, de contorno poligonal y sus paredes de reacción lipofílica positiva (Fig. 3F; Tabla 5). Las células secretoras, frecuentemente se disponen en forma de arco debajo del haz vascular, pero también se ubican en el parénquima sobre el haz vascular. Tanto en el floema como en el parénquima de la vena media hay drusas. El mesofilo presenta las mismas características que I. cairica (Tabla 2).

Pecíolo.- Se diferencia de I. cairica por ser pubescente y por tener mayor cantidad de drusas y estructuras secretoras (conductos y células) en el parénquima cortical reservante.

\section{Lonicera japonica}

Lámina.- En vista frontal la epidermis adaxial muestra células poligonales con paredes anticlinales rectilíneas, mientras que en la cara abaxial son curvadas, con engrosamientos y campos de puntuaciones primarias (Fig. 4A). La continuidad de la epidermis abaxial es interrumpida por numerosos estomas anomocíticos con engrosamiento polar y distribuidos de manera desordenada (Fig. 4A; Tablas 3 y 4). Sobre las venas, en ambas epidermis, hay gran cantidad de tricomas glandulares y eglandulares cuya densidad disminuye en forma directamente proporcional con el diámetro de las venas; los tricomas no se hallan sobre la parte media de la lámina, por ello no figuran en la tabla 3. Los tricomas glandulares son uniseriados, presentan un cuerpo 3-4 celular y la cabeza globosa pluricelular. Los eglandulares son unicelulares con paredes gruesas y verrucosos. Profundizando el enfoque desde ambas epidermis se pueden observar las drusas en el mesofilo. En la sección transversal las 
Tabla 5. Compuestos identificados, estructuras secretoras y cristales hallados en las hojas de las especies estudiadas. Ref.: (ES) estructura secretora; (+) presencia; (--) ausencia.

\begin{tabular}{|l|c|c|c|c|c|c|}
\hline \multicolumn{1}{|c|}{ Taxa } & Almidón & Lípidos & Mucílagos & Taninos & ES & Cristales \\
\hline $\begin{array}{l}\text { Araujia } \\
\text { odorata }\end{array}$ & + & + & -- & + & + & drusas \\
\hline $\begin{array}{l}\text { Araujia } \\
\text { sericifera }\end{array}$ & + & + & -- & - & + & drusas \\
\hline $\begin{array}{l}\text { Canavalia } \\
\text { bonariensis }\end{array}$ & + & + & + & -- & -- & $\begin{array}{c}\text { solitarios } \\
\text { m maclas }\end{array}$ \\
\hline $\begin{array}{l}\text { Clematis } \\
\text { bonariensis }\end{array}$ & -- & + & -- & -- & -- & -- \\
\hline $\begin{array}{l}\text { Clematis } \\
\text { montevidensis }\end{array}$ & -- & + & -- & -- & -- & - \\
\hline $\begin{array}{l}\text { Ipomoea } \\
\text { cairica }\end{array}$ & + & + & + & -- & + & drusas \\
\hline $\begin{array}{l}\text { Ipomoea } \\
\text { indica }\end{array}$ & + & + & + & -- & + & drusas \\
\hline $\begin{array}{l}\text { Lonicera } \\
\text { japonica }\end{array}$ & -- & + & -- & -- & -- & drusas \\
\hline $\begin{array}{l}\text { Muehlenbeckia } \\
\text { sagittifolia }\end{array}$ & + & + & + & + & -- & drusas \\
\hline $\begin{array}{l}\text { Passiflora } \\
\text { caerulea }\end{array}$ & -- & + & -- & + & -- & drusas \\
\hline $\begin{array}{l}\text { Tropaeolum } \\
\text { majus }\end{array}$ & + & + & + & -- & + & -- \\
\hline $\begin{array}{l}\text { Tropaeolum } \\
\text { pentaphyllum }\end{array}$ & -- & + & + & -- & + & drusas \\
\hline
\end{tabular}

epidermis son unistratas, las células de la epidermis adaxial de contorno rectangular con engrosamientos en las paredes, cubiertas por cutícula relativamente gruesa y de tamaño notoriamente más grandes que en la epidermis abaxial (Fig. 4B). En esta, los estomas se ubican elevados con respecto a las restantes células epidérmicas (Fig. 4B, C). La vena media muestra convexidad adaxial (Tabla 2) y en posición subepidérmica hay 2-3 capas de colénquima angular, adaxial y abaxial; en posición medular se halla un haz con forma de arco (Tabla 2), circundado por parénquima, donde al igual que en el floema se visualizan numerosas drusas. El mesofilo está formado por parénquima en empalizada de células cortas y en mayor proporción parénquima esponjoso laxo, abaxial (Fig. 4B; Tabla 2). En este último se observan células idioblásticas con drusas y los haces vasculares de menor tamaño presentan vaina parenquimática (Fig. 4B).

Pecíolo.- Pubescente en toda su periferia, en corte transversal es de contorno semicircular, con la cara ventral convexa (Fig. 4D). La epidermis está formada por células rectangulares con su eje más largo perpendicular a la superficie, con pared periclinal externa engrosada y cutícula delgada, lisa. En posición subepidérmica, se localizan 1-4 capas de colénquima angular, contínuo, seguido de parénquima cortical con drusas y gotas lipídicas. En el sector medular hay un haz colateral en forma de arco, el cual presenta en el floema drusas menores que las del parénquima cortical y junto al mismo una capa amilífera (Fig. 4D; Tabla 5). 

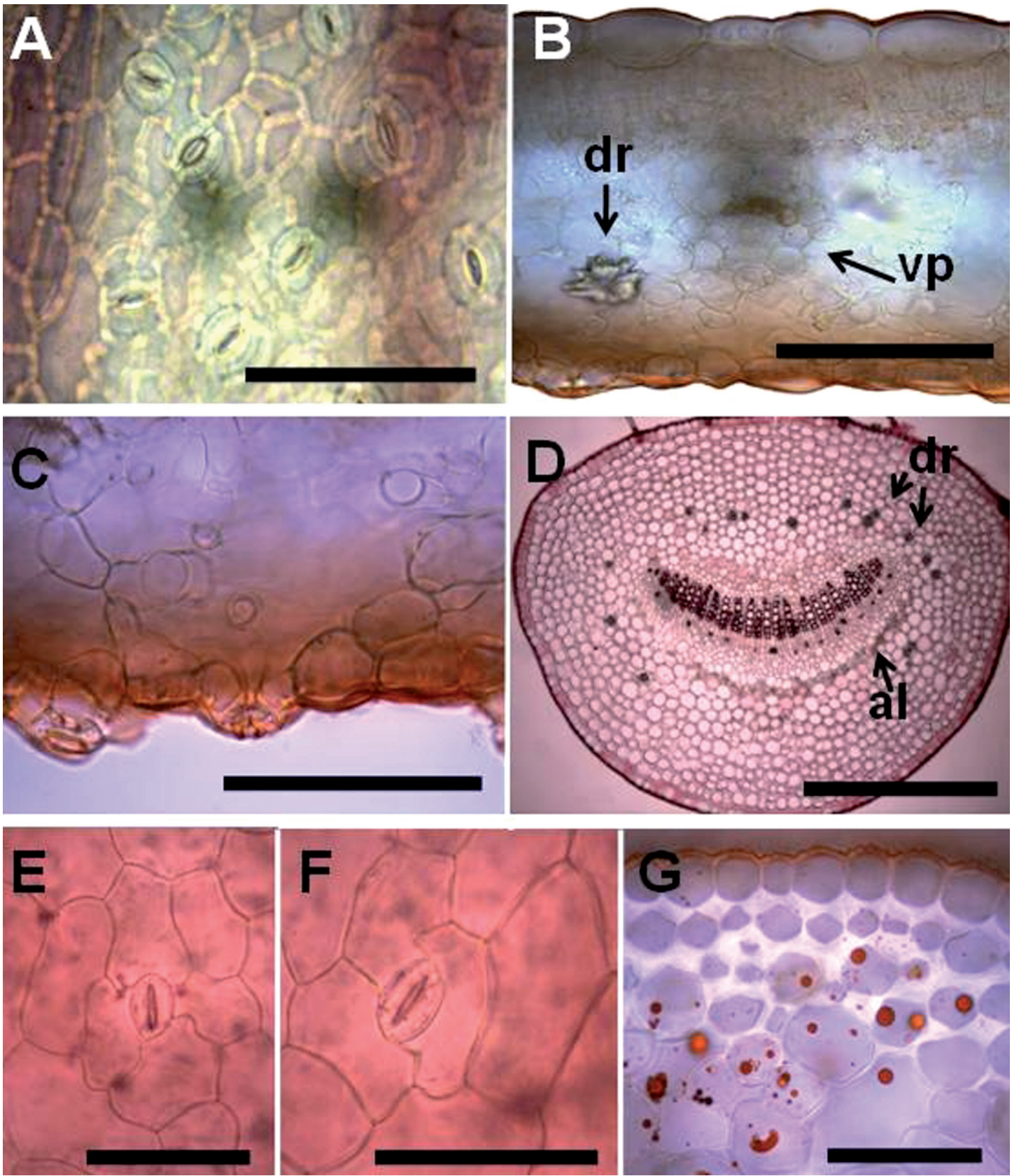

Fig. 4. Lonicera japonica y Muehlenbeckia sagittifolia. A-D) L. japonica. A) Epidermis abaxial mostrando las células epidérmicas con paredes anticlinales engrosadas, estomas anomocíticos; células oclusivas con engrosamiento polar. B) Sección transversal de la lámina mostrando las epidermis adaxial y abaxial y el mesofilo dorsiventral con predominio del parénquima esponjoso, laxo y en él la presencia de drusas y un haz menor con vaina parenquimática. C) Detalle de la epidermis abaxial con estomas elevados respecto a las restantes células epidérmicas. D) Sección transversal del pecíolo semicircular mostrando los tejidos y el haz medular en forma de arco. E-G) M. sagittifolia. E) Estoma anomocítico. F) Estoma anisocítico. G) Porción de la sección transversal del pecíolo mostrando epidermis con la cutícula teñida con Oil Red "O», gotas de aceites dispersas en colénquima y parénquima. Ref.: al, almidón; dr, drusas; vp, vaina parenquimática. Escalas: A-C, E-G: $100 \mu \mathrm{m}$; D: $500 \mu \mathrm{m}$. 


\section{Muehlenbeckia sagittifolia}

Lámina.- En vista frontal la epidermis adaxial muestra células poligonales con paredes anticlinales curvadas hasta onduladas y la abaxial onduladas. Los estomas, son anomocíticos y anisocíticos, predominando los anisocíticos, distribuidos de manera desordenada (Fig. 4E, F). Profundizando el enfoque se observan drusas en el mesofilo. En la sección transversal las epidermis son unistratas, las células de la epidermis adaxial y abaxial son rectangular-globosas, cubiertas por cutícula delgada; de tamaño ligeramente más grandes en la epidermis adaxial que en la abaxial. Algunos estomas en la epidermis adaxial y numerosos en la abaxial, se hallan ubicados a nivel o levemente elevados con respecto a las restantes células epidérmicas. La vena media presenta convexidad adaxial (Tabla 2); en posición subepidérmica hay 3-4 capas de colénquima adaxial y 1-2 capas hacia la cara abaxial; dos haces colaterales enfrentados, uno adaxial y otro abaxial, ambos con el xilema interno, separados y rodeados por parénquima. El mesofilo está formado por parénquima en empalizada adaxial y parénquima esponjoso laxo, abaxial (Tabla 2). En el mesofilo esponjoso se observan células idioblásticas con drusas, gran cantidad de gotas de aceites y los haces vasculares menores con vaina parenquimática notable.

Pecíolo.- Glabro, con cinco lóbulos, de los cuales, los dos ventrales, prominentes, están irrigados por haces menores. La epidermis está formada por células redondeadas con cutícula delgada notablemente estriada. En posición subepidérmica hay 1-5 capas de colénquima angular, discontinuo, seguido de parénquima cortical donde se observan numerosas drusas y gotas lipídicas (Fig. 4G; Tabla 5). El tejido vascular (excluyendo los haces de los lóbulos ventrales), está formado por cuatro haces vasculares colaterales, tres de ellos en los lóbulos dorso-laterales y uno mayor, hacia la cara ventral. La médula amplia, es parenquimática.

\section{Passiflora caerulea}

Lámina.- En vista frontal las epidermis, adaxial y abaxial, muestran células poligonales con paredes anticlinales rectilíneas engrosadas y abundantes ceras epicuticulares. Los estomas son anomocíticos y anisocíticos, ocasionalmente paracíticos (Fig. 5A). Profundizando el enfoque desde ambas caras de la lámina diafanizadas se pueden observar las drusas en el mesofilo, predominantemente en las venas. En la sección transversal las epidermis son unistratas, las células de la epidermis adaxial son cuadrangulares, con paredes periclinales externas y anticlinales engrosadas, cubiertas por cutícula gruesa y de mayor tamaño que en la epidermis abaxial, donde la continuidad se ve interrumpida por los estomas, éstos están hundidos, principalmente porque las células epidérmicas presentan la pared periclinal externa convexa. $\mathrm{La}$ vena media presenta la cara adaxial cóncava (considerando la vena y alas) (Fig. 5B; Tabla 2); en posición subepidérmica hay 1-2 capas de colénquima angular adaxial y abaxial; en posición medular un haz con drusas en el floema y en el parénquima que lo rodea (Fig. 5B; Tabla 5). El mesofilo está formado por parénquima en em- 

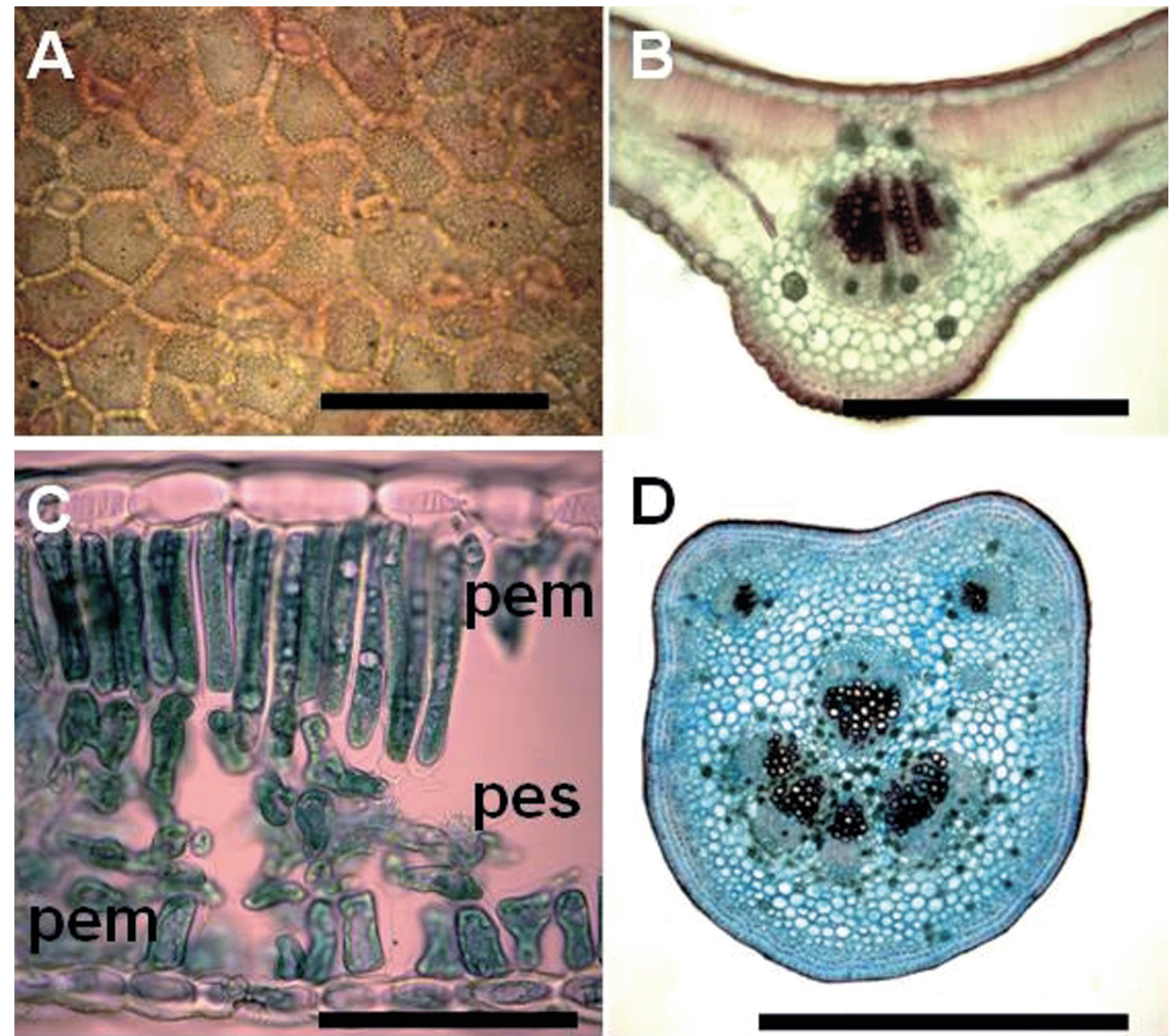

Fig. 5. Passiflora caerulea. A) Epidermis abaxial mostrando las células epidérmicas con paredes anticlinales engrosadas, estomas anomocíticos y anisocíticos y abundantes ceras epicuticulares. B) Sección transversal de la lámina mostrando la vena media cóncavo-convexa, drusas en el parénquima de la vena. C) Detalle del mesofilo isolateral con escasa diferenciación del parénquima en empalizada abaxial. D) Sección transversal del pecíolo mostrando un haz irrigando cada lóbulo ventral y en el sector medular cinco haces abaxiales, uno ventral. Ref.: pem, parénquima en empalizada; pes, parénquima esponjoso. Escalas: A, C: $100 \mu \mathrm{m}$; B: $400 \mu \mathrm{m}$; D: $1000 \mu \mathrm{m}$.

palizada adaxial y abaxial y entre ellos el parénquima esponjoso laxo (Fig. 5C). En todo el mesofilo se observan células idioblásticas con drusas y los haces vasculares de menor tamaño que se localizan en el parénquima esponjoso presentan vaina parenquimática notable.

Pecíolo.- Glabro, en corte transversal con la cara ventral levemente cóncava y dos lóbulos redondeados irrigados por los respectivos haces vasculares (Fig. 5D). La epidermis está formada por células cuadrangulares con paredes gruesas (colenquimática), cubierta por cutícula gruesa. En posición subepidérmica, 1-3 capas de colénquima angular discontinuo que alterna con clorénquima. El parénquima cortical interno amilífero, presenta cristales solitarios y drusas. El tejido vascular está formado por 4-5 haces colaterales abaxiales y un haz colateral adaxial mayor (Fig. 5D; Tabla 5). 


\section{Tropaeolum majus}

Lámina._- En vista frontal la epidermis adaxial y abaxial muestran células poligonales con paredes anticlinales curvadas hasta onduladas, cubiertas por abundantes ceras epicuticulares. En ambas epidermis se hallan estomas anomocíticos y anisocíticos (Fig. 6A). La epidermis abaxial posee mayor número de estomas y también tricomas simples, uniseriados, pluricelulares, de contorno más o menos cónico, con 3-4(-10) células (Fig. 6B; Tablas 3 y 4). En la base hay notables células, generalmente una mucilaginífera. En la sección transversal las epidermis son unistratas. En ambas epidermis las células son elipsoidales con paredes delgadas y las periclinales convexas, cubiertas por cutícula delgada; los estomas están hundidos entre las células epidérmicas papilosas. La vena media muestra la cara adaxial convexa (Fig. 6C; Tabla 2); en posición subepidérmica hay 1-2 capas de colénquima lagunar adaxial y una capa abaxial; en posición medular un haz con canales secretores esquizógenos en la zona cambial del haz (Fig. 6C, D). El mesofilo está formado por parénquima en empalizada de células rectangulares proporcionalmente largas y parénquima esponjoso abaxial, laxo (Tabla 2). En este último se observan los haces vasculares de menor tamaño con vaina parenquimática notable.

Pecíolo.- Glabro, de contorno circular en corte transversal. La epidermis presenta células cuadrangulares con paredes delgadas, cubiertas por una cutícula delgada. En posición subepidérmica hay una capa de colénquima angular-lagunar continuo, seguido de 6-7 estratos de parénquima cortical amiláceo. El sistema vascular está formado por 7-8 haces vasculares colaterales dispuestos en un círculo dejando en su interior la amplia médula parenquimática.

\section{Tropaeolum pentaphyllum}

Lámina.- Se diferencia de T. majus por tener estomas solo en la epidermis abaxial y de tipo anomocítico (Tabla 2). Profundizando el enfoque desde ambas epidermis se pueden observar las drusas dispersas en el mesofilo. La forma de la vena media en corte transversal y la estructura de la vena media y alas de la lámina (Fig. 6E, F), son coincidentes con lo descripto para T. majus, con excepción de que en $T$. pentaphyllum a nivel de la vena media, hay 2-3 capas de parénquima colenquimatoso hacia ambas epidermis (Fig. 6E).

Pecíolo.- La estructura se diferencia del pecíolo de T. majus por la presencia de un anillo de 2-4 estratos de fibras esclerenquimáticas que separa el parénquima cortical del medular y rodea a cuatro haces vasculares colaterales (Fig. 6G); estos están dispuestos en un círculo encerrando al parénquima medular el cual contiene drusas. 

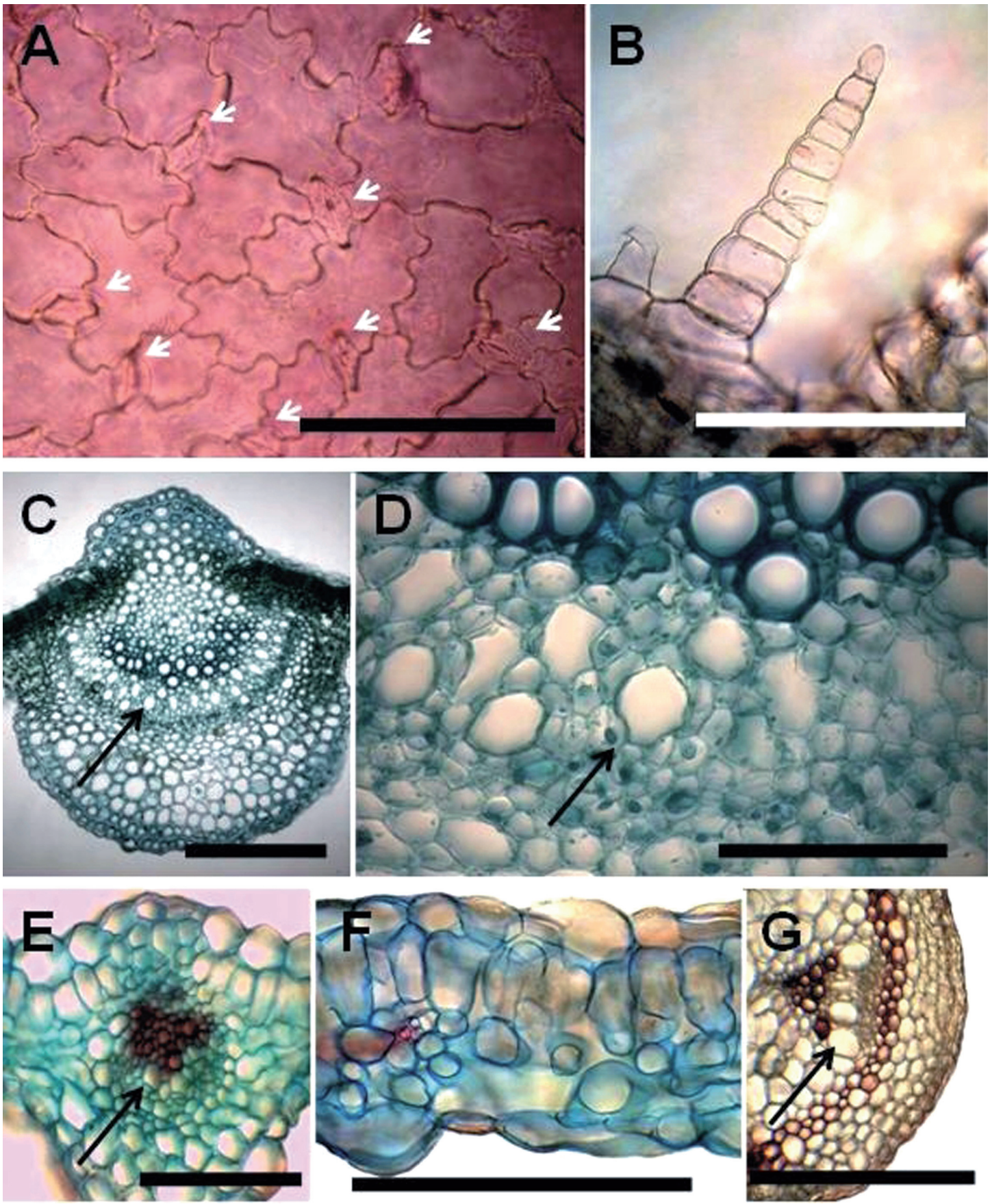

Fig. 6. Tropaeolum majus y T. pentaphyllum. A-D) T. majus. A) Epidermis abaxial mostrando las células epidérmicas con paredes anticlinales ondulado-sinuosas y estomas anomocíticos y anisocíticos (flechas). B) Tricoma abaxial. C) Sección transversal de la vena media biconvexa, se han señalado las estructuras secretoras a nivel del cambium vascular. D) Detalle de las estructuras secretoras cambiales. E-G) T. pentaphyllum. E) Sección transversal de la vena media biconvexa. F) Sección transversal de las alas, mostrando las células papilosas de ambas epidermis, el mesofilo delgado formado por una capa en empalizada y pocas de parénquima esponjoso. G) Parte de la sección transversal del pecíolo mostrando el anillo de fibras y un haz vascular donde con flecha se señalan las estructuras secretoras cambiales. A, D, F: $100 \mu \mathrm{m}$; B, E: $200 \mu \mathrm{m}$; C: $400 \mu \mathrm{m}$; G: $500 \mu \mathrm{m}$. 


\section{Clave para la determinación de las especies estudiadas}

1 Vena media en el corte transversal de la lámina, biconvexa con convexidad adaxial notablemente aguda, triangular. El pecíolo presenta una capa de hipodermis con drusas

1' Vena media en el corte transversal de la lámina plana o cóncava en la cara adaxial, o si es biconvexa, la convexidad adaxial obtusa. El pecíolo nunca presenta hipodermis con drusas

2 Hoja hipostomática. Vena media en corte transversal con conductos esquizógenos en el parénquima Ipomoea cairica

2' Hoja anfistomática. Vena media en corte transversal con conductos esquizógenos y células laticíferas en el parénquima

I. indica

3 Epidermis abaxial con maclas gemelas. Haces vasculares con vaina cristalífera Canavalia bonariensis

3' Epidermis abaxial y haces vasculares sin esas características ............................. 4

4 Presencia de drusas ........................................................................................ 5

4' Ausencia de drusas ............................................................................................ 10

5 Vena media en el corte transversal con tubos laticíferos conspicuos en el parénquima sobre y bajo el haz vascular bicolateral ................................................... 6

5. Vena media en el corte transversal sin tubos laticíferos en el parénquima y sin haces vasculares bicolaterales .................................................................................. 7

6 Estomas hundidos respecto al resto de las células epidérmicas. Hoja anfistomática ……................................................................................... Araujia odorata

6' Estomas a nivel respecto al resto de las células epidérmicas. Hoja hipostomática A. sericifera

7 Células epidérmicas con paredes anticlinales rectilíneas, notablemente engrosadas

7 Células epidérmicas con paredes anticlinales curvadas, curvado-onduladas hasta sinuosas, delgadas

8 Vena media en corte transversal con la cara adaxial cóncava (cóncavo-convexa). Estomas hundidos con respecto al resto de las células epidérmicas. Pecíolo glabro Passiflora caerulea

8' Vena media en corte transversal con la cara adaxial convexa (biconvexa). Estomas elevados con respecto al resto de las células epidérmicas. Pecíolo pubescente Lonicera japonica

9 Vena media en corte transversal con dos haces colaterales enfrentados. Pecíolo de contorno pentalobado, sin anillo esclerenquimático

Muehlenbeckia sagittifolia

9' Vena media en corte transversal con un solo haz colateral central. Pecíolo de contorno circular, con anillo esclerenquimático Tropaeolum pentaphyllum

10 Células epidérmicas con paredes anticlinales ondulado-sinuosas. Vena media con la cara adaxial convexa (biconvexa) T. majus

10' Células epidérmicas con paredes anticlinales rectilíneas. Vena media con la cara adaxial plana o cóncava (plano-convexa o cóncavo-convexa) 
11 Índice estomático adaxial no mayor a $2 \%$

Clematis bonariensis

11' Índice estomático adaxial mayor a $8 \%$ C. montevidensis

\section{DISCUSIÓN}

Los caracteres anatómicos hallados en las hojas de $A$. odorata y A. sericifera coinciden con los datos aportados por Bayón y Arambarri (1999) y Mercado et al. (2017). También se encontró coincidencia con la descripción de las características epidérmicas y estructurales de la hoja de $A$. sericifera reportada por Bucciarelli et al. (2008). Canavalia bonariensis tiene características de la estructura foliar acordes con la familia e indicados en numerosos estudios (e. g., Freire et al., 2005). Se hallaron cristales gemelos en la epidermis, característica indicada para otras especies del género por Metcalfe y Chalk (1950). En Clematis montevidensis los resultados estuvieron de acuerdo con lo reportado por Pérez Cuadra (2012). Al comparar los microcaracteres de las dos especies estudiadas ( $C$. bonariensis y $C$. montevidensis) se halló una gran similitud y sus características se corresponden con las de la familia de acuerdo con Metcalfe y Chalk (1950). En las especies de Ipomoea son conspicuas las estructuras de secreción, conductos y células, estableciendo por histoquímica que los conductos poseen aceites en las células epiteliales y las células secretoras, por su aspecto poligonal en el corte transversal y coloración tomada por las paredes celulares, serían las células laticíferas «que secretan sustancia lechosa», mencionadas por Metcalfe y Chalk (1950). En Lonicera japonica se hallaron estomas anomocíticos característicos de la familia Caprifoliaceae (Metcalfe y Chalk, 1950; Freire et al., 2005). El mesofilo dorsiventral y la presencia de tricomas glandulares y eglandulares están de acuerdo con lo indicado para Sambucus nigra de la misma familia por Ponessa y Parrado (2001). Sin embargo, en Sambucus se encontró arena cristalina (Ponessa y Parrado, 2001; Freire et al., 2005) mientras que no se observó la presencia de estos cristales en la estructura foliar de Lonicera japonica. Passiflora es un género con numerosas especies de importancia en el campo de la medicina. En Brasil, para asegurar la identificación de material de uso medicinal se han realizado numerosos estudios de las hojas de Passiflora (e. g., P. actinia, P. alata, P. edulis). En la región rioplatense habita P. caerulea y al comparar los resultados con los de otras especies, se observa que el carácter más estable en su diferenciación es la forma de la vena media en sección transversal y su sistema vascular. En $P$. caerulea la sección de la vena es cóncavo-convexa y posee un solo haz vascular colateral, una forma similar posee P. alata (Pereira et al., 2009), mientras que resulta más frecuente la forma biconvexa y con varios haces vasculares colaterales distribuidos en círculo, los que fueron indicados para P. actinia (Kurtz et al., 2003), P. edulis (Pereira et al., 2009; Beraldo y Kato, 2010) y en P. guazumaefolia y $P$. aff. tiliaefolia (García et al., 2008). En P. caerulea se observaron estomas anomocíticos, anisocíticos y paracíticos coincidiendo con los tipos de estomas hallados por Metcalfe y Chalk (1950) y Barboza et al. (2001). Si bien se coincide en los tipos de estomas citados en la bibliografía, la predominancia de uno u otro parece ser una característica diferencial entre especies y aquí nuevamente se encontró una mayor coincidencia entre los rasgos de $P$. caerulea y $P$. alata, donde predominan los anomo- 
cíticos y anisocíticos sobre los paracíticos. La abundancia de ceras epicuticulares observadas en $P$. caerulea, son mencionadas para la epidermis de P. actinia (Kurtz et al., 2003), sin embargo $P$. caerulea no posee la epidermis abaxial papilosa como $P$. actinia. Estos caracteres son de valor taxonómico (Kurtz et al., 2003). La ausencia de tricomas es otra semejanza entre las especies $P$. actinia, $P$. alata y $P$. caerulea. Dos diferencias son factibles de destacar en $P$. caerulea con respecto a las restantes especies mencionadas en los párrafos precedentes: las células epidérmicas con paredes anticlinales rectilíneas y presencia de un mesofilo isolateral. Estas características y los estomas hundidos además muestran una adaptación a condiciones xéricas que tendría $P$. caerulea, no presente en $P$. actinia, $P$. alata, $P$. edulis, $P$. guazumaefolia y $P$. aff. tiliaefolia. En Tropaelum majus y T. pentaphyllum la micrografía mostró coincidencia con la descripción general de las hojas de T. incisum (Bulacio et al., 2017). Las diferencias si bien existen, son caracteres influenciables por el ambiente, tales como el mesofilo que es isolateral en T. incisum mientras que se halló dorsiventral en T. majus y T. pentaphyllum. Con respecto a la distribución de los estomas en una o ambas epidermis de la lámina, coinciden T. incisum y T. majus con sus láminas anfistomáticas, mientras que es hipostomática en T. pentaphyllum. En el pecíolo hay un carácter de interés en taxonomía, como la presencia de un anillo esclerenquimático limitando externamente la eustela; este anillo se halló en T. pentaphyllum al igual que en T. incisum (Bulacio et al., 2017), pero estuvo ausente en el pecíolo de T. majus. La epidermis de las especies de Tropaeolum estudiadas presentan células papilosas en las que se analizó la presencia de mirosina con el reactivo de Millon obteniendo resultado negativo, esto se atribuye a que como Metcalfe y Chalk (1950) lo señalan, esta proteína se encuentra principalmente en raíz y tallo, no en hojas.

\section{CONCLUSIÓN}

Se ha profundizado el conocimiento de la anatomía foliar, cualitativa y cuantitativa, de las doce especies estudiadas. La riqueza de características estructurales de la hoja permitió generar una clave para la identificación de los taxa analizados, constituyendo una importante herramienta con valor en el control de calidad botánica.

\section{AGRADECIMIENTOS}

A la Secretaría de Ciencia y Técnica de la Universidad Nacional de La Plata por el financiamiento económico de los estudios en el marco del Programa de incentivos a los docentes-investigadores. A los revisores anónimos por el aporte realizado con sus comentarios. 


\section{BIBLIOGRAFÍA}

Arambarri, A. M. (2018). La «técnica de clarificación 5-5-5», un método natural para el tratamiento de material vegetal. Boletín de la Sociedad Argentina de Botánica 53 (4): 579-586.

Arambarri, A. M., Novoa M. C., Hernández M. P., Colares M. N. y Perrotta V. G. (2013). Anatomía de Dicotiledóneas: tallos de hierbas terrestres medicinales rioplatenses (Buenos Aires, Argentina). Bonplandia 22 (2): 5-28.

Arambarri, A. M., Hernández M. P., Perrotta V. G., Colares M. N. y Novoa M. C. (2016). Anatomía de los órganos subterráneos de Monocotiledóneas medicinales rioplatenses (Argentina). I. Acuáticas y palustres. Lilloa 53: 157-172.

Ash, A., Ellis B., Hickey L. J., Johnson K., Wilf P. y Wing S. (1999). Manual of leaf architecture - morphological description and categorization of dicotyledonous and net-veined monocotyledonous angiosperms by Leaf architecture working group. Washington, D. C., USA: Smithsonian Institution.

Barboza, G. E., Bonzani N., Filippa E. M., Luján M. C., Morero R., Bugatti M., Decolatti N. y Ariza Espinar L. (2001). Atlas histo-morfológico de plantas de interés medicinal de uso corriente en Argentina. Còrdoba, Argentina: Museo Botánico, Serie Especial 1.

Barboza, G. E., Cantero J. J., Núñez C. O. y Ariza Espinar L. (2006). Flora medicinal de la provincia de Córdoba (Argentina), Museo Botánico de Córdoba: Gráficamente ediciones.

Barboza, G. E., Cantero J. J., Núñez C., Pacciaroni A. y Ariza Espinar L. (2009). Medicinal plants: A general review and a phytochemical and ethnopharmacological screening of the native Argentine Flora. Kurtziana 34 (1-2): 7-365.

Bayón, N. D. y Arambarri A. M. (1999). Anatomía y etnobotánica de las especies medicinales de la Provincia Pampeana: Asclepiadaceae. Acta Farmacéutica Bonaerense 18 (2): 23-31.

Beraldo, J. y Kato E. T. M. (2010). Morfoanatomía de folhas e caules de Passiflora edulis Sims, Passifloraceae. Revista Brasileira de Farmacognosia 20 (2): 233-239.

Bucciarelli, A., Cambi V. N. y Villamil C. B. (2008). Morfoanatomía de Araujia hortorum E. Fourn. (Asclepiadaceae), especie nativa de interés medicinal. Phyton 77: 283-295.

Bulacio, E., Mercado M. I. y Ponessa G. I. (2017). Morfología y anatomía de órganos vegetativos de Tropaeolum incisum (Tropeolaceae). Lilloa 54 (2): 110-122.

Cabanillas, P. A. y Hurrell J. A. (2012). Plantas trepadoras: tipo biológico y clasificación. Ciencias Morfológicas 14 (2):1-15.

Colares, M. N., Hernández M. P., Novoa M. C., Perrotta V. G., Auguet S. y Arambarri A. M. (2014). Anatomía comparada de raíces medicinales de hierbas terrestres rioplatenses (Buenos Aires, República Argentina). Dominguezia 30 (1): 5-18.

Colares, M. N., Martínez Alonso S. M. y Arambarri A. M. (2016). Anatomía e histoquímica de Tarenaya hassleriana (Cleomaceae), especie de interés medicinal. Boletín Latinoamericano y del Caribe de Plantas Medicinales y Aromáticas 15 (3): 182-191. 
Colares, M. N., Martínez Alonso S. M., Spegazzini E., Hernández M. P., Perrotta V. G., Novoa M. C. y Arambarri A. M. (2017). Anatomía e histoquímica de los órganos subterráneos de plantas trepadoras medicinales rioplatenses (Argentina). Lilloa 54 (2): 123-140.

Cosa, M. T., Dottori N., Stiefkens L., Hadid M., Matesevach M., Delbón N., Wiemer P. Machado S., Cabrera V., Costa C., Pérez A. y Trenchi A. (2014). Aplicaciones de técnicas de histología vegetal a la resolución de diversos problemas. Còrdoba, Argentina: Laboratorio de Morfología Vegetal, Facultad de Ciencias Exactas, Físicas y Naturales, Universidad Nacional de Córdoba.

Domínguez, J. A. (1928). Contribuciones a la materia médica argentina. Instituto de Botánica y Farmacología, Buenos Aires: Peuser.

Freire, S. E., Arambarri A. M., Bayón N. D., Sancho G., Urtubey E., Monti C., Novoa M. C. y Colares M. N. (2005). Epidermal characteristics of toxic plants for cattle from the Salado River Basin (Buenos Aires, Argentina). Boletín de la Sociedad Argentina de Botánica 40 (3-4): 241-281.

García, M., Jáuregui D. y Pérez D. (2008). Anatomía foliar de Passiflora guazumaefolia Juss. y Passiflora aff. tiliaefolia L. (Passifloraceae) presentes en Venezuela. Ernstia 18 (2): 165-176.

Gasparotto, A. Jr., Boffo M. A., Lourenço E. L., Stefanello M. E., Kazuya C. A. y Marques M. C. (2009). Natriuretic and diuretic effects of Tropaeolum majus (Tropeolaceae) in rats. Fournal of Ethnopharmacology 122 (3): 517-522.

Gurr, E. (1971). Synthetic dyes in biology, medicine and chemistry. London, England: Academic Press.

Hernández, M. y Albornoz P. (2001). Morfología y anatomía foliar en especies de Cheilanthes (Pteridaceae) del noroeste argentino. Lilloa 40 (2): 187-207.

Hernández, M. P., Colares M. N. y Civitella S. M. (2009). Plantas utilizadas en medicina popular en un sector del Partido de Berisso, Buenos Aires, Argentina. Boletín Latinoamericano y del Caribe de Plantas Medicinales y Aromáticas 8 (5): 435-444.

Hernández, M. P., Civitella S. M. y Rosato V. G. (2010). Uso medicinal popular de plantas y líquenes de la Isla Paulino, provincia de Buenos Aires, Argentina. Boletín Latinoamericano y del Caribe de Plantas Medicinales y Aromáticas 9 (4): 258-269.

Hernández, M. P., Novoa M. C., Civitella S. M., Mason D. y Oviedo A. (2013). Plantas usadas en la medicina popular en la Isla Santiago, Buenos Aires, Argentina. Boletín Latinoamericano y del Caribe de Plantas Medicinales y Aromáticas 12 (4): 385-399.

Hernández, M. P., Novoa M. C., Arambarri A. M. y Oviedo M. A. (2015a). Plantas medicinales y para condimento usadas en el sudeste del partido de Berisso (Buenos Aires, Argentina). Bonplandia 24 (2): 125-138.

Hernández, M. P., Novoa M. C., Colares M. N., Perrotta V. G., Nughes L. M. y Arambarri A. M. (2015b). Anatomía foliar de hierbas terrestres medicinales que crecen en la región rioplatense (Buenos Aires, Argentina). Bonplandia 24 (2): $97-123$. 
Hieronymus, G. (1882). Plantas diaphoricae florae argentinae. Buenos Aires: Kraft.

Hiriart, F. D., Cabanillas P. A., Apodaca M. J., Benedictto M., Barral L. y Guerrero E. L. (2018). Listado comentado de las plantas vasculares trepadoras y epífitas de la costa rioplatense del Partido de Quilmes (Buenos Aires, Argentina). Boletín de la Sociedad Argentina de Botánica 53 (1): 103-113.

Instituto de Botánica Darwinion. Disponible: http://www2,darwin.edu.ar/floraargentina/fa.htm. (Consultado: julio 2018).

Johansen, D. A. (1940). Plant microtechnique. New York, USA: McGraw-Hill Book Company.

Kurtz, S., Santos C., Duarte M. y Sato M. (2003). Morfo-anatomia de folhas de maracujá: Passiflora actinia Hooker, Passifloraceae. Acta Farmacéutica Bonaerense 22 (2): 105-112.

Lahitte, H. B. y Hurrell J. A. (1996). Las plantas de la medicina popular de la isla Martín García. Buenos Aires, Argentina: Comisión de Investigaciones Científicas de la provincia de Buenos Aires.

Lahitte, H. B. y Hurrell J. A. (2000). Plantas trepadoras. Nativas y exóticas. Buenos Aires, Argentina: Literature of Latin America (LOLA).

Lahitte, H. B., Hurrell J. A., Belgrano M. J., Jankowski L. S., Haloua M. P. y Mehltreter K. (2004). Plantas medicinales rioplatenses. Buenos Aires, Argentina: Literature of Latin America (LOLA).

Luque, R., Sousa H. C. y Kraus J. E. (1996). Métodos de coloração de Roeser (1972) —modificado - e Kropp (1972) visando a substituição do azul de astra por azul de alcião 8 GS ou 8GX/Staining methods of modified Roeser (1972) and Kropp (1972), aiming at substituting the astra blue by alcian blue $8 \mathrm{GS}$ or $8 \mathrm{GX}$. Acta Botanica Brasilica 10 (2): 199-212.

Martínez, G. J. (2017). Las plantas en la medicina tradicional de las sierras de Córdoba: un recorrido por la cultura campesina de Paravachasca y Calamuchita. Córdoba: Detodoslosmares.

Martínez Crovetto, R. (1981). Plantas utilizadas en medicina en el noroeste de Corrientes (República Argentina). Tucumán: Miscelánea (Fundación Miguel Lillo) 69: 1-139.

Marzocca, A. (1997). Vademécum de malezas medicinales de la Argentina indígenas y exóticas. Buenos Aires, Argentina: Orientación Gráfica.

Mercado, M. I., Álvarez M. A. y Ponessa G. I. (2017). Morfoanatomía e histoquímica de tallo y hojas de Araujia odorata (Apocynaceae), Tucumán (Argentina). XXXVI Jornadas Argentinas de Botánica. Boletín de la Sociedad Argentina de Botánica 52 (S): 20.

Metcalfe, C. R. y Chalk L. (1950). Anatomy of the Dycotiledons 1 y 2: 1-1499. Oxford, England: University Press.

Metcalfe, C. R. y Chalk L. (1979). Anatomy of the Dicotyledons. Oxford, England: Clarendon Press.

Novoa, M. C. y Arambarri A. M. (2016). Importance of anatomical leaf-blade features for characterization of medicinal Commelinaceae in the Rio de la Plata area 
(Buenos Aires, Argentina). Boletín de la Sociedad Argentina de Botánica 51 (3): 419-427.

Novoa, M. C., Colares M. N. y Arambarri A. M. (2012). Anatomy of Monocotyledons: stems and rhizomes of land herbs used as medicinal in the Rio de la Plata area (Argentina). Bonplandia 21 (2): 53-61.

Pereira, C. S., Kurita H., Vega R., Jiménez M., Molinas C. y Benítez F. B. (2009). Evaluación de la morfo-anatomía foliar de Passiflora alata Curtis y Passiflora edulis Sims. Steviana 1 (1): 38-45.

Pérez Cuadra, V. (2012). Anatomía ecológica de la vegetación del Salitral de la Vidriera. (Tesis Doctoral), Universidad Nacional del Sur, Buenos Aires, Argentina.

Perrotta, V. G., Hernández M. P. y Arambarri A. M. (2017). Anatomía de los órganos subterráneos de cuatro Dicotiledóneas medicinales rioplatenses (Argentina). II. Plantas palustres. Lilloa 54 (2): 229-239.

Pochettino, M. L., Martínez M. R., Itten B. y Zucaro M. (1997). Las plantas medicinales como recurso terapéutico en una población urbana: estudio etnobotánico en Hernández (Pdo. La Plata, Prov. Buenos Aires, Argentina). Parodiana 10 (1-2): 141-152.

Ponessa, G. y Parrado M. F. (2001). Caracterización anátomo foliar y aspectos etnobotánicos de Sambucus nigra L. subsp. peruviana (Kunth) R. Bolli (Caprifoliaceae). Acta Farmacéutica Bonaerense 20 (3): 173-179.

Rapoport, E. H., Marzocca A. y Drausal B. S. (2009). Malezas comestibles del Cono Sur y otras partes del planeta. Bahia Blanca: Universidad Nacional del Comahue, INTA, CONICET, Secretarias de Ambiente y Desarrollo Sustentable, Fundación Normatil.

Ratera, E. y Ratera M. (1980). Plantas de la flora argentina empleadas en medicina popular. Buenos Aires: Hemisferio Sur.

Rondina, R. V. D., Bandoni A. L. y Coussio J. D. (2008). Especies medicinales argentinas con potencial actividad analgésica. Dominguezia 24 (1): 47-69.

Rondina, R. V. D., Bandoni A. L. y Coussio J. D. (2010). Argentine medicinal plants with potential antifungal activity. Dominguezia 26 (1): 31-39.

Ruzin, S. E. (1999). Plant microtechnique and microscopy. Oxford, England: University Press.

Salisbury, E. (1927). On the causes and ecological significance of stomatal frequency with special reference to the woodland flora. Philosophical Transactions of the Royal Society of London B 216: 1-65.

Spegazzini, E. (2007). La micrografía en la identidad de los vegetales. Boletín Latinoamericano y del Caribe de Plantas Medicinales y Aromáticas 6 (7): 165.

Ulibarri, E. A., Gómez Sosa E. V., Cialdella A. M., Fortunato R. y Bazzano D. (2002). Leguminosas. Nativas y exóticas. En: J. A. Hurrell , H. B. Lahitte. (Eds.), Biota rioplatense 7 (pp. 222-223). Buenos Aires: Literature of Latin America (LOLA).

Volkmann, L. (2017). 60 plantas medicinales de la Argentina Central. S. M. Cochetti (Ed.). Córdoba: Detodoslosmares.

Zarlavsky, G. E. (2014). Histología vegetal. Técnicas simples y complejas. Córdoba: Sociedad Argentina de Botánica. 
Zornig, H. y Weiss G. (1925). Beiträge Zur. Anatomie des Laubblattes offizineller und pharmäzeutixch gebräuchlicher Compositen-Drogen. Archiv der Pharmazie Berlin 263: 451-470.

\section{APÉNDICE}

Lista en orden alfabético de nombres científicos de las especies estudiadas, con nombre vulgar de uso frecuente, uso popular y actividad biológica. Los usos están referidos a las hojas.

Araujia odorata «tasi fragante». El látex de las hojas es utilizado como galactógeno, analgésico, en odontalgia, como antiverrucoso y como goma de mascar (Lahitte et al., 2004; Mercado et al., 2017).

Araujia sericifera «tasi». La infusión de las hojas y frutos es galactógena, es decir, se consumen para aumentar la secreción de leche de las madres que amamantan (Lahitte y Hurrell, 2000). El látex, en buches, actúa como analgésico (Lahitte et al., 2004; Rondina et al., 2008) y el látex del fruto tiene actividad proteolítica (Barboza et al., 2009), propiedad como antimicótico (Rondina et al., 2010).

Canavalia bonariensis «isipó». La infusión de las hojas tomada bien caliente calma los trastornos digestivos (principalmente estomacales) (Lahitte y Hurrell, 2000; Ulibarri et al., 2002; Lahitte et al., 2004).

Clematis bonariensis "cabello de ángel». Las hojas se aplican en cataplasmas como antineurálgicas, cáusticas y rubefacientes. Sirve para curar las lastimaduras agusanadas de los animales, como antídoto de mordeduras de víboras y picaduras de arañas, contra la hidrofobia por mordeduras de perros. La infusión de las hojas se usa para combatir las pecas, lepra, sarna y otras enfermedades cutáneas. Posee un principio tóxico por lo cual solo se emplea externamente (Hieronymus, 1882; Domínguez, 1928; Lahitte y Hurrell, 1996; Lahitte y Hurrell, 2000; Lahitte et al., 2004).

Clematis montevidensis «cabello de ángel». Posee los mismos usos que C. bonariensis (Lahitte y Hurrell, 2000). Las partes aéreas frescas o su decocción sirven como desinfectante para lavar las regiones afectadas por micosis (Lahitte y Hurrell, 1996; Rondina et al., 2010; Martínez, 2017). Tendrían propiedad analgésica (Rondina et al., 2008). El test biológico indica las partes aéreas con actividad antibacterial y diurética (Barboza et al., 2009).

Ipomoea cairica e I. indica «campanillas». Poseen los mismos usos en medicina tradicional. El cocimiento de las hojas se bebe como purgante, febrífugo y antihidrópico. En fomentos se aplica como vulnerario y antidermatósico (Lahitte y Hurrell, 2000; Lahitte et al., 2004). Los tallos tiernos y hojas de I. cairica son comestibles (Rapoport et al., 2009) y en medicina sus hojas también son usadas como cicatrizante (Marzocca, 1997; Volkmann, 2017). Las partes aéreas tienen actividad citotóxica (Barboza et al., 2006; 2009). 
Lonicera japonica «madreselva». Martínez Crovetto (1981) indicó que la decocción de las hojas se bebe "contra la maldad», uso válido de acuerdo a Lahitte y Hurrell (1996) en la isla Martín García.

Muehlenbeckia sagittifolia «zarzaparrilla colorada». La decocción de las hojas se emplea como depurativa, cardiotónica, antisifilítica, diurética y hepática; en uso externo como tópico es astringente y vulneraria (Lahitte y Hurrell, 2000; Lahitte et al., 2004). La parte aérea tiene actividad antibacterial (Barboza et al., 2009).

Passiflora caerulea "pasionaria». Las especies de Pasiflora poseen las principales propiedades como sedativo y ansiolítico; es tónico y regulador del sistema nervioso (Martínez Crovetto, 1981; Lahitte y Hurrell, 1996; Kurtz et al., 2003). La infusión de las hojas se emplea como sedante y para calmar palpitaciones y molestias del corazón (Martínez, 2017). Las hojas se indican como vermífugas (Ratera y Ratera, 1980; Lahitte et al., 2004). Las hojas por su principio activo con actividad depresiva, se usan como hipotensivas, anticefalálgico, bradicárdico, sedativo (Barboza et al., 2009).

Tropaeolum majus «taco de reina». Las hojas se consumen en ensaladas (Rapoport et al., 2009). La infusión posee propiedades como antiescorbútico por ser ricas en vitamina C (Lahitte y Hurrell, 1996; Lahitte et al., 2004). En aplicación externa su propiedad es como analgésico (Lahitte y Hurrell, 2000). Es un agente diurético (Gasparotto et al., 2009), también empleado en infecciones urinarias y desordenes cardiovasculares (Bulacio et al., 2017).

Tropaeolum pentaphyllum «flor de pitito». Las hojas y flores se consumen como antiescorbúticas (Lahitte y Hurrell, 1996, 2000; Lahitte et al., 2004). Otro uso es como ornamental (Bulacio et al., 2017). 